\title{
A Brief Review of Viscosity Models for Slag in Coal Gasification
}

\author{
Mehrdad Massoudi* and Ping Wang \\ U.S. Department of Energy \\ National Energy Technology Laboratory (NETL) \\ 626 Cochrans Mill Road \\ P.O. Box 10940 \\ Pittsburgh, PA 15236-0940 \\ USA \\ MASSOUDI@NETL.DOE.GOV \\ (412)386-4975
}

*corresponding author

Report Number: DOE/NETL-2012/1533

November 2011 


\section{Table of Contents}

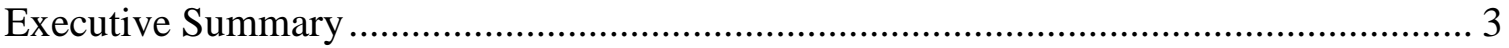

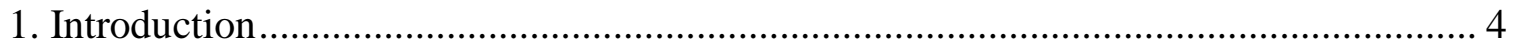

1.1 Slag and Ash Formation ............................................................................... 4

1.2 Blast Furnaces and Continuous Casting.............................................................. 5

1.3 Co-firing and Other Uses of Slags ……………................................................ 7

1.4 Computational Fluid Dynamics and Multiphase Issues ........................................ 7

2. Governing Equations of Motion and Heat Transfer ..................................................... 10

2.1 Single Phase (Component) Approach....................................................................... 10

2.2 Multi-Phase (Component) Approach ........................................................................ 11

3. The Importance of Slag Layer Viscosity in Gasfication and Combustion Processes... 15

3.1 Viscosity of Slags ............................................................................................ 15

3.2. A Brief Review of Various Viscosity Models ……….......................................... 17

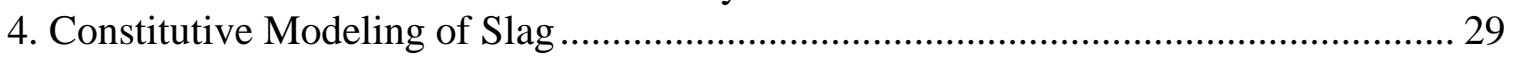

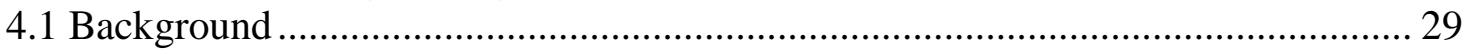

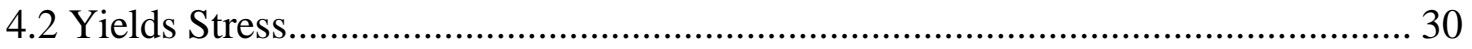

4.3 Effects of Concentration, Shear Rate, Temperature, and Pressure .......................... 32

4.3.1 Concentration Effect .................................................................................. 32

4.3.2 Normal Stress Effects and Shear-Rate Dependent Viscosity ........................... 33

4.3.3 Temperature Effect ........................................................................................ 35

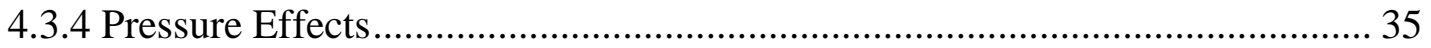

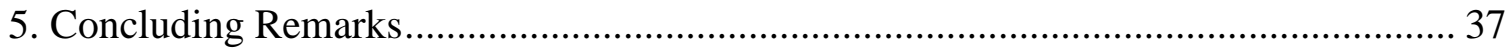

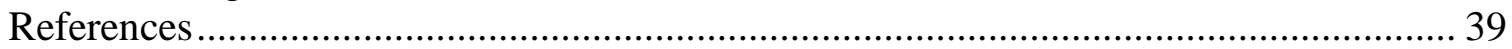




\section{EXECUTIVE SUMMARY}

Many researchers have defined the phenomenon of "slagging" as the deposition of ash in the radiative section of a boiler, while "fouling" refers to the deposition of ash in the convective-pass region. Among the important parameters affecting ash deposition that need to be studied are ash chemistry, its transport, deposit growth, and strength development; removability of the ash deposit; heat transfer mechanisms; and the mode of operation for boilers. The heat transfer at the walls of a combustor depends on many parameters including ash deposition. This depends on the processes or parameters controlling the impact efficiency and the sticking efficiency. For a slagging combustor or furnace, however, the temperatures are so high that much of the coal particles are melted and the molten layer, in turn, captures more particles as it flows. The main problems with ash deposition are reduced heat transfer in the boiler and corrosion of the tubes. Common ways of dealing with these issues are soot blowing and wall blowing on a routine basis; however, unexpected or uncontrolled depositions can also complicate the situation, and there are always locations inaccessible to the use of such techniques. Studies have indicated that slag viscosity must be within a certain range of temperatures for tapping and the membrane wall to be accessible, for example, between $1300^{\circ} \mathrm{C}$ and $1500{ }^{\circ} \mathrm{C}$, the viscosity is approximately $25 \mathrm{~Pa} \cdot \mathrm{s}$. As the operating temperature decreases, the slag cools and solid crystals begin to form. In such cases the slag should be regarded as a nonNewtonian suspension, consisting of liquid silicate and crystals. A better understanding of the rheological properties of the slag, such as yield stress and shear-thinning, are critical in determining the optimum operating conditions.

To develop an accurate heat transfer model in any type of coal combustion or gasification process, the heat transfer and to some extent the rheological properties of ash and slag, especially in high-temperature environments need to be understood and properly modeled. The viscosity of slag and the thermal conductivity of ash deposits are among two of the most important constitutive parameters that need to be studied. The accurate formulation or representations of the (transport) properties of coal (and biomass for co-firing cases) present a special challenge of modeling efforts in computational fluid dynamics applications.

In this report, we first provide a brief review of the various approaches taken by different researchers in formulating or obtaining a slag viscosity model. In general, these models are based on experiments. Since slag behaves as a non-linear fluid, we discuss the constitutive modeling of slag and the important parameters that must be studied. 


\section{INTRODUCTION}

\subsection{Slag and Ash Formation ${ }^{1}$}

Deposition of ash in fluidized-bed combustion is primarily caused by the transfer of molten mineral matter from the burning char onto the bed surface. Two possible mechanisms have been proposed for this unwanted phenomenon: (1) partial melting or reactive liquid sintering, and (2) viscous flow sintering. (See Tonmukayakul and Nguyen, 2002.) The first situation occurs with partial melt at $500-700^{\circ} \mathrm{C}$, which is normally lower than the standard operating temperatures of many fluidized beds. The second mechanism occurs at temperatures about or higher than $1000{ }^{\circ} \mathrm{C}$, creating a highly viscous and nonlinear fluid. At such high temperatures, the standard methods of measuring viscosity do not always work.

Heat transfer at the walls of a combustor depends on many parameters including ash deposition. This depends on the processes or parameters controlling the impact efficiency and the sticking efficiency. For the sticking rate, Walsh et al (1992) and Lee et al. (1999) have suggested that the viscosity of the particles and the deposition surface are the most important parameters. These studies were limited to isothermal cases. For a slagging combustor or furnace, however, the temperatures are so high that much of the coal particles are melted and the molten layer, in turn, captures more particles as it flows. Wang et al (2007, 2011) suggested a simple model for running slag using the basic Newtonian viscosity assumption with additional shear stresses on the surface of the running slag, which are due to the swirling gas and the deposition of particles. They state that to understand the properties of particle deposition one must know the arrival rate, the deposition rate, the wall burning rate, the velocity of the running slag, etc. The main problems with ash deposition are reduced heat transfer in the boiler and corrosion of the tubes. Common ways of dealing with these issues are soot blowing and wall blowing on a routine basis; however, unexpected or uncontrolled depositions can also complicate the situation and there are always locations inaccessible to the use of such techniques. Wang and Harb (1997) list eight important concepts which should be included or addressed in any formation of ash deposits modeling: (1) understating the process of ash formation, (2) understanding the fluid dynamics and the equations governing the particle transport, (3) the process of particle impacts and sticking to the surfaces, (4) the location of deposit growth in the combustion chamber, (6) heat transfer mechanisms through the deposit layers, (7) the effect of deposition on temperatures and heat fluxes, etc., and (8) the structure of deposit and how this affects the flow patterns in the combustion facility.

It has been suggested that two different mechanisms dominate and control the process of ash deposition and deposit growth. The first one is due to van der Waals force, generally for small ash particles that are moving due to turbulent diffusion or thermophoresis effects. The second parameter is a viscosity-dependent and surface tension-driven model. Erickson et al. (1995) proposed three distinct layers, which include (1) an initial layer deposit formed by small ash particles, (2) a bulk layer formed from the partially molten ash and the non-deformable particles captured by the deposit surface,

\footnotetext{
${ }^{1}$ This report is a follow-up or a companion report to a recently published report titled: "Effect of Coal Properties and Operation Conditions on Flow Behavior of Coal Slag in Entrained Flow Gasifiers: A Brief Review,” by P. Wang and M. Massoudi, report number: DOE/NETL-2011/1508.
} 
and (3) a slag layer flowing as a viscous fluid. One of the main reasons for using an entrained-flow gasifier is that the highest temperature can be achieved in the entrainedflow slagging process ( $\mathrm{Ni}$ et al. 2011). It should be noted that, in addition to viscosity, thermal conductivity, and the emissivity of the deposits, two other important parameters in these situations depend on the temperature and the degree of sintering. Next to the viscosity of ash or slag, thermal conductivity is the most important physical /material parameter. The ash deposits are porous and they can be approximated as packed beds. For a detailed analysis and a discussion of the relevant issues to heat transfer in ash deposits, we refer the reader to the review article by Zbogar et al. (2005).

One of the major parameters in the design and operation of the power generation processes is the knowledge of the melting behavior of the coal mineral. Jak et al. (2000) mention that the major components of coal slags produced in combustion or gasification processes are based on $\mathrm{FeO}-\mathrm{Fe}_{2} \mathrm{O}_{3}-\mathrm{CaO}-\mathrm{SiO}_{2}-\mathrm{Al}_{2} \mathrm{O}_{3}$ chemical composition. Interestingly, the chemistry of many metallurgical smelting operations also depend on a similar chemical compositions but with seven components, instead of five, namely, $\mathrm{PbO}-\mathrm{ZnO}-\mathrm{FeO}-\mathrm{Fe}_{2} \mathrm{O}_{3}-\mathrm{CaO}-\mathrm{SiO}_{2}-\mathrm{Al}_{2} \mathrm{O}_{3}$. In their study, they used a modified quasi-chemical model for the molten slag phase, and the thermodynamic modeling was based on the FACT computer system (see Bale et al., 1996). As Jak et al., (2000) mention: "The slag composition and operating temperature should be such that a small temperature decrease in the reactor or a small variation in slag chemistry does not lead to a large increase in the fraction of solids in the slag." This is an issue related to the control of the slag layer, where it is preferable for the slag behave like a fluid so that it can be tapped from the reactor. For a recent review of the many important issues in gasification, including slag formation, we refer the reader to the review article by Breault (2010).

A common definition of "slagging" is the deposition of ash in the radiative section of a boiler, while "fouling" refers to the deposition of ash in the convective-pass region (see Erickson et al. 1995). Ash chemistry is among the important parameters affecting ash deposition that needs to be studied, specifically its transport, deposit growth and strength development, removability of the deposit, heat transfer mechanisms, and the mode of operation for the boilers (see Erickson et al 1995). Slag and ash also occur in ignite-fired power plants whose main characteristics are a high water and ash content (see Papastergios et al., 2007). Vorres et al., (1986) observed that in regions where there is a large amount of iron present in the coal ash, especially in the eastern parts of the United States, in the more oxidizing environment of a boiler, coal slags behave more like a highly polymerized fluid than in the less oxidizing environments such as the slagging gasifier or cyclone combustor (see Lawn 1987).

As Jak et al. (2004) observed, at a typical section of slag deposit on the walls of a reactor, the temperature at the water-cooled wall of a gasifier can be taken to be $\sim 450{ }^{\circ} \mathrm{C}$, while the temperature at the slag surface is $\sim 1450{ }^{\circ} \mathrm{C}$. Such a sharp gradient causes various types of responses including the creation of different sub-layers.

\subsection{Blast Furnaces and Continuous Casting}

In recent years, one of the approaches to improve the production efficiency of blast furnaces has been to include low slag volume by using high pulverized coal injection (PCI) operation. In many cases, as Kang et al., (2005) observed, the fluidity of 
blast furnace slag is controlled by changing the slag chemistry, for example, by modifying the "burden practice" such as the amount of supplementary materials and the quality of sinter. An important parameter in these operations is the "wettability," a response that occurs when a liquid is brought into contact with a solid surface and that depends on whether the process is reactive or not, as well as many other parameters such as temperature, solute aggregation, phase formation, chemical reaction, etc. Kang et al., (2005) indicate that not only is the viscosity of slag important in these operations, but also coke/slag interactions, which could significantly impact the liquid permeability of the blast furnace. While in the blast furnace, operations slag is composed of $\mathrm{Al}_{2} \mathrm{O}_{3}-\mathrm{CaO}$ $\mathrm{MgO}-\mathrm{SiO}_{2}$, and the refining slags are based on $\mathrm{Al}_{2} \mathrm{O}_{3}-\mathrm{CaO}-\mathrm{SiO}_{2}$ system. The importance of the structural role of $\mathrm{Al}_{2} \mathrm{O}_{3}$ in silicate melts is an important subject of study (see Shu 2009).

One of the recent advances in blast furnace technology is pulverized coal injection through tuyeres to partially replace metallurgical coke as a source of heat (see Mehta and Sahajwalla 2003). However, the high injection rates necessary for increased efficiency can seriously challenge the stability and integrity of the furnace due to the amount of unburnt char. In general, the blast furnace slags are composed of iron oxide, silica, alumina, lime, etc., with iron oxide and silica playing the major roles in the temperature range $1500-1700{ }^{\circ} \mathrm{C}$.

In the continuous casting of steel, when mold powder is added to the free surface of the liquid steel, it begins to melt and flow. The re-solidified mold powder, also called slag, forms a layer adjacent to the walls; there is an increase in its viscosity and it begins to act as a solid-like material (see Meng and Thomas 2003a,b). Once the slag cools, a glassy layer is created. Heat conduction across the slag layer plays a major role in the operation; it is a function of the thickness of the slag and depends on the conductivity of the various layers and particles embedded in the slag. In the continuous casting of steel, the viscosity of the molten slag or flux varies with the composition of the various elements present and the temperature. For example, most commercial fluxes contain 0$13 \% \mathrm{Al}_{2} \mathrm{O}_{3}, 22-45 \% \mathrm{CaO}$, and $17-56 \% \mathrm{SiO}_{2}$, with small amounts of fluorides ( $\mathrm{NaF}$, $\mathrm{CaF}_{2}$ ), alkalis $\left(\mathrm{Na}_{2} \mathrm{O}, \mathrm{K}_{2} \mathrm{O}\right)$ and other basic oxides ( $\mathrm{MgO}, \mathrm{BaO}$ ) (see Zhao et al., 2005).

There is a great deal of similarity in the processes involving steel production and those of slag in coal gasification or combustion processes. Important issues in thermal processing of steel ingots include thermal stress modeling and panel cracking (see Thomas et al. 1987a,b). Another important area of research in the steel industry is the conversion to continuous casting from ingot casting, a process which is driven by improved efficiency, yield and higher quality steel (see Kelly et al., 1988). In this case, the thermal fluxes change and new models must be developed. For example, the molten steel contained within the solidifying shell in the continuous casting process resembles the slag layer. Thomas et al., (1990) seem to be among the first researchers who attempted to develop a comprehensive mathematical model involving fluid flow, heat transfer, shrinkage, and stress generation in such a slab-casting mold. They used the $\mathrm{K}-\varepsilon$ equation of turbulence to simulate the turbulent flow field in the mold region.

Heat transfer plays a major role in the solidification process, which occurs in continuous casting technology in the steel industry; this includes factors such as friction and lubrication at solid-liquid interfaces, high temperatures due to the high heat flux in 
the mould, etc. (Mazumdar and Ray, 2001). Slag viscosity is an important element in this process since the motion of the mould relative to the solidified shell produces a frictional force, which is related to the viscosity of the slag.

\subsection{Co-firing and Other Uses of Slags}

The world demand for building supplies requires large amounts of raw materials. A new emerging area is the use of slag from the industrial streams, such as blast furnaces slag, in building materials (see Karamanova et al., 2011). There have also been studies on freeze-thaw cycle on alkali-activated slag concrete (see Fu et al., 2011). Slag cement and other viscosity modifying admixtures (VMAs) have been used in recent years in selfconsolidating concrete (SCC) with some success (see Lachemi et al., 2003).

As fossil fuel use increases, the amount of waste materials and the environmental issues dealing with their disposal also increase. One of the promising approaches is the development of coal/waste co-firing technology with fuels such as biomass. Biomass constitutes an estimated 14\% of the world energy use, which makes it the fourth largest energy source (see Ekmann et al., 1998). Biomass can comprise wood residues, agricultural residues (crops, foods, animals), municipal solid waste, etc. (see Easterly and Burnham 1996). Additionally, energy crops, including short-rotation woody crops and herbaceous crops such as tall switch grass, are predicted to become the largest source of biomass in the future. In general, biomass fuels are converted to energy via thermal, biological, and physical processes. Bridgwater (2003) and Bridgwater et al., (2002) indicate that the three primary thermal processes for converting biomass to useful energy are combustion, gasification, and pyrolysis. Coal can be used as the primary fuel for high temperature environments such as the open-cycle Magneto-hydrodynamics MHD generators where coal particles are burnt in the combustion chamber with temperatures and pressures in the order of $3000 \mathrm{~K}$ and $10 \mathrm{~atm}$, respectively. Under these hightemperature and high-pressure conditions, the dynamics of coal particles change significantly. As mentioned by Sondreal et al., (2001) high temperatures are needed for most advanced combustion technologies, including those using co-firing biomass with fossil fuels, to improve the thermodynamic efficiencies, which in turn raises problems associated with high temperature such as corrosion and deposition by coal ash and slag.

Slagging combustors have been used in more recent MHD applications (see Petrick and Shumyatsky 1978) in conjunction with an advanced gasifier system, known as the MEET (Multistaged Enthalpy Extraction Technology) (see Pian and Yoshikawa 2001). According to these researchers, improvements in coal gasification, cleanup, turbine generators, system integration, etc., improve efficiency in integrated gasification combined cycle (IGCC) plants.

\subsection{Computational Fluid Dynamics (CFD) and Multiphase Issues}

One way of improving the efficiency in IGCC processes is to use a two-stage feeding, which involves a combustion stage and a reduction stage with a gasifier. Chen et al., (2001) developed a numerical model for a two-phase type flow, using the K- $\varepsilon$ turbulence model for the gas and a particle dispersion model, emphasizing that the movement of particles is the primary parameter determining the local fuel-O stoichiometric ratio, which is important in controlling the overall carbon conversion. 
The accurate formulation or representations of the (transport) properties of coal (and biomass for co-firing cases) present a special challenge of modeling efforts in computational fluid dynamics (CFD) applications. For example, we do not possess a good knowledge of the specific heats of coals as a function of temperature at high heating rates (see Williams et al., (2000). As pointed out by Backreedy et al., (2005), in most CFD studies related to coal combustion, the effects of gravity are assumed to be negligible. This is not a good assumption, since in many processes, especially co-firing with biomass, $10-40 \%$ of the ash can fall into the bottom ash hopper.

Flowing mixtures (multicomponent or multi-phase ${ }^{2}$ flows) consisting of solid particles entrained in a fluid are relevant to a variety of applications such as fluidized beds and pneumatic or hydraulic transport of solid particles. The primary approach for describing and analyzing coal furnaces and combustors has generally been accomplished through experimental studies where empirical correlations are used to describe the complex flows and chemical reactions that occur. Traditionally designers have relied on experiments to produce empirical formulas and correlations. One obvious difficulty with this approach is that, in general, changing the experiment or some of the conditions such as geometry, inlet conditions, particle loading, etc., may change the outcome and hence produce different correlations. This approach is now being augmented with theoretical and computational modeling techniques, which provide design engineers with the predictive capability and the freedom to choose and change conditions leading to a better design of combustors with higher efficiency, optimum geometry, less pollution, etc. In recent years, many CFD codes have been developed. An important issue is the physical models which are embedded in these codes; most of these models are linear constitutive equations. Bjorkvall, et al., (2001) presented a multi-component model where the oxide activities, the determining or the driving force of the chemical reactions, was obtained based on the experimental information corresponding to the binary subsystem. Some of the carbon associated with char particles are unburnt and are transferred to the molten ash slag. Montagnaro and Salatino (2010) studied the coal particles in an entrained gasifier in the slagging regime. They developed a simple one-dimensional model of the gasifier by suggesting that the gasifier can be divided into three components, namely, a leandispersed phase, a wall ash layer, and a dense-dispersed phase. Ni et al. (2011) used a Eulerian-Lagrangian approach to study the flow of the gas and particle phases.

Among the computational codes one can name the particle-size and composition distribution (PSCD) of the ash produced in combustion and other simplified transport models. However, as Ma et al., (2007) observed, there does not seem to be a comprehensive and integrative approach in the codes to predict the deposit formation and growth in specific areas and its impact on the total heat transfer in the boiler. Ma et al., (2007) present their results based on a computer code named AshPro ${ }^{\text {SM }}$, which can obtain information about slagging and fouling at specific localized points.

\footnotetext{
${ }^{2}$ Although the two terms, multi-component or multi-phase, are used interchangeably in the literature, multi-component (or two-component for simple cases) is more accurate. This goes back to the early days of the theory where a two-phase flow usually referred to water and vapor (bubbles) — two phases of the same material. However, later on the term was retained even for cases such as solid particles (for example, coal) and water or air. In the latter case, the term "two-component" should be used, since coal is not a phase of water (or air).
} 
One of the latest studies by Koric and Thomas (2008) considers two different elastic visco-plastic models for the behavior of steel solidification. To do their study, they used a model developed by Anand (1982) in the commercially available code ANSYS and the model by Kozlowski et al., (1992)/Zhu (1993) using commercially available code ABAQUS. In both classes of models the strain rates are given by experimentally obtained/fitted correlations that are functions of temperature, stresses, chemical composition, etc.

To develop an accurate heat transfer model in any type of coal combustion or gasification process, the heat transfer and to some extent the rheological properties of ash and slag, especially in high-temperature environments need to be understood and modeled properly. It has been recognized that the viscosity of slag and the thermal conductivity of ash deposits are two of the most important constitutive parameters that must be studied. As Rezaei et al (2000) state, the latter depends on the porosity, chemical composition, temperature of the deposit, etc. They observed that the thermal conductivity of ash increases with increasing temperature, but decreases with increasing porosity. Noticeably, the thermal conductivity of slags was found to be higher than that of the particulate structure in the porosity range $0.2-0.8$.

In the next section of this report, we present the basic governing equations for the flow of slag under three conditions: (1) slag as a non-homogeneous and non-linear single component material (the emphasis in this Report); (2) slag as a part of a multi-component or a two-component system (such as gasification) where generally a two-fluid (EulerianEulerian) approach is used; and (3) slag as a part of a (dilute) multi-component (Lagrangian-Eulerian) system. 


\section{GOVERNING EQUATIONS OF MOTION AND HEAT TRANSFER}

\subsection{Single Phase (Component) Approach}

If slag is treated as a single component (phase) material, then, in the absence of any electro-magnetic effects, the governing equations of motion are the conservation of mass, linear momentum, convection-diffusion, and energy equations (see Slattery 1999):

$$
\begin{aligned}
& \text { Conservation of mass: } \\
& \qquad \frac{\partial \rho}{\partial t}+\operatorname{div}(\rho \mathbf{u})=0
\end{aligned}
$$

where $\rho$ is the density of the fluid, $\partial / \partial t$ is the partial derivative with respect to time, and $\mathbf{u}$ is the velocity vector. For an isochoric motion, we have $\operatorname{div} \mathbf{u}=0$.

Conservation of linear momentum:

$$
\rho \frac{\mathrm{d} \mathbf{u}}{\mathrm{dt}}=\operatorname{div} \mathbf{T}+\rho \mathbf{b} \text {. }
$$

where $\mathbf{b}$ is the body force vector, $\mathbf{T}$ is the Cauchy stress tensor, and $\mathrm{d} / \mathrm{dt}$ is the total time derivative, given by $\frac{\mathrm{d}(.)}{\mathrm{dt}}=\frac{\partial(.)}{\partial \mathrm{t}}+[\operatorname{grad}().] \mathbf{u}$. The balance of moment of momentum reveals that, in the absence of couple stresses, the stress tensor is symmetric.

Conservation of Concentration:

$$
\frac{\partial \mathrm{c}}{\partial \mathrm{t}}+\operatorname{div}(\mathbf{c u})=\mathrm{f}
$$

where $\mathrm{c}$ is the concentration and $\mathrm{f}$ is a constitutive parameter. This equation is also known as the convection-reaction-diffusion equation.

$$
\begin{aligned}
& \text { Conservation of Energy: } \\
& \qquad \rho \frac{\mathrm{d} \varepsilon}{\mathrm{dt}}=\mathbf{T} \cdot \mathbf{L}-\operatorname{divq}+\rho r
\end{aligned}
$$

where $\varepsilon$ is the specific internal energy, $\mathbf{L}$ is the gradient of velocity, $\mathbf{q}$ is the heat flux vector, and $r$ is the radiant heating ${ }^{3}$. Thermodynamical considerations require the

\footnotetext{
${ }^{3}$ Constitutive relations for complex materials can be obtained in different ways using (a) continuum mechanics, (b) physical and experimental models, (c) numerical simulations, (d) statistical mechanics approaches, and (e) ad hoc approaches. A look at the governing equation (1-4) reveals that constitutive relations are required for $\mathbf{T}, \mathbf{q}, \mathrm{f}, \boldsymbol{\varepsilon}$, and $\mathrm{r}$. Less obvious is the fact that in many practical problems involving competing effects, such as temperature and concentration, the body force $\mathbf{b}$, which in problems dealing with natural convection oftentimes depends on the temperature and is modeled using the Boussinesq assumption, now might have to be modeled also as a function of concentration. Furthermore,
} 
application of the second law of thermodynamics or the entropy inequality. The local form of the entropy inequality is given by the following (see Liu 2002, p. 130):

$$
\rho \dot{\eta}+\operatorname{div} \varphi-\rho s \geq 0
$$

where $\eta(\mathbf{x}, t)$ is the specific entropy density, $\varphi(\mathbf{x}, t)$ is the entropy flux, and $s$ is the entropy supply density due to external sources, and the dot denotes the material time derivative. If it is assumed that $\varphi=\frac{1}{\theta} \mathbf{q}$, and $s=\frac{1}{\theta} \mathrm{r}$, where $\theta$ is the absolute temperature, then equation (5) reduces to the Clausius-Duhem inequality:

$$
\rho \dot{\eta}+\operatorname{div} \frac{\mathbf{q}}{\theta}-\rho \frac{\mathrm{r}}{\theta} \geq 0
$$

Even though we do not consider the effects of the Clausius-Duhem inequality in our problem, for a complete thermo-mechanical study of this problem, the Second Law of Thermodynamics must be considered (see Müller 1967, Ziegler 1983, Truesdell and Noll 1992, Liu 2002). In order to "close" these equations, we must provide constitutive relations for $\mathbf{T}, \mathbf{q}, \mathrm{f}, \varepsilon$, and $\mathrm{r}$.

\subsection{Multi-Phase (Component) Approach}

If the slag is modeled as a multi-component material, then the governing equations should be given for all the components. Historically, two distinct approaches have been used to study multi-component flows. In the first case, the amount of the dispersed phase is so small that the motion of this component does not greatly affect the motion of the continuous phase. This is generally known as the "dilute phase approach," sometimes called the Lagrangian approach. This method has been used extensively in applications such as atomization, sprays, and in flows where bubbles, droplets, and particles are treated as the dispersed phase. In the second approach, the two constituents are interacting with each other so that each phase (or component) directly influences the motion and the behavior of the other phase. This is known as the "dense phase approach," sometimes called the Eulerian (or the two-fluid) approach ${ }^{4}$. This method is used extensively in fluidization, gas-solid flows, pneumatic conveying (see Massoudi 2002, 2003 and the list of references therein).

Although the Mixture Theory and Averaging Methods seem similar, the way they approach the formulation of constitutive models are very different. The details of Mixture

in many problems involving chemical reactions, there is usually a (heat) source term, Q, in equation (2.4), which also must be constitutively modeled (see Straughan, 2004, 2008; Massoudi and Phuoc, 2008).

${ }^{4}$ The expression Eulerian-Eulerian approach is a rather poor expression, and in fact a misleading one. Of course, what is meant is that the Eulerian (spatial) description of the motion is used for the two components, as opposed to the Lagrangian (material or particle) description. One should be extremely cautious here, for one can also have a two component flow of two Eulerian fluids, in which (1) a compressible Eulerian (elastic, inviscid) fluid is represented by $T=-p(\rho) I$, where the pressure is a function of density (see Truesdell and Rajagopal, 2000 p. 143), and (2) an incompressible Eulerian (elastic, inviscid) fluid defined through $\boldsymbol{T}=-p \boldsymbol{I}$, where $\mathrm{p}$ is indeterminate. However, in most of the studies, the fluids in question are viscous fluids. 
Theory (or Theory of Interacting Continua) are given in books by Truesdell (1984) and Rajagopal and Tao (1995). Review articles by Atkin and Craine (1976a, b) and Bowen (1976) discuss specific issues and the important problems in Mixture Theory. The foundation of this theory is based on a homogenization approach in which each component is regarded as a single continuum, and, at each instant of time, every point in space is considered to be occupied by a particle belonging to each component of the mixture. Conservation laws are then written for each component that take into account interaction with other constituents. The balance laws for the mixture can also be obtained for the mixture as a whole. Constitutive relations are needed to "close" the governing equations. The Mixture Theory equations for a multi-component system are as follows (see Atkin and Craine 1976a, b; Beevers and Craine 1982):

Mass:

$$
\frac{\mathrm{D}^{(\alpha)} \rho_{\alpha}}{\mathrm{Dt}}+\rho_{\alpha} \operatorname{div} \mathbf{v}^{(\alpha)}=\mathrm{m}_{\alpha} ; \quad \alpha=1,2
$$

Momentum:

$$
\rho_{\alpha} \frac{\mathrm{D}^{(\alpha)} \mathbf{v}}{\mathrm{Dt}}=\operatorname{div} \mathbf{T}^{(\alpha)}+\boldsymbol{\pi}^{(\alpha)}-\mathrm{m}_{\alpha}\left(\mathbf{v}^{(\alpha)}-\mathbf{J}^{\alpha}\right)+\rho_{\alpha} \mathbf{F}^{\alpha}
$$

Moment of Momentum:

$$
\mathbf{T}_{\mathrm{s}}^{(\alpha)}=\lambda^{(\alpha)}
$$

Energy:

$$
\begin{array}{r}
\rho_{\alpha} \frac{\mathrm{D}^{(\alpha)} \mathrm{U}_{\alpha}}{\mathrm{Dt}}=\rho_{\alpha} \mathrm{r}_{\alpha}-\operatorname{div} \mathbf{q}^{(\alpha)}+\psi_{\alpha}+\operatorname{tr}\left(\mathbf{T}_{\mathrm{s}}^{(\alpha)} \mathbf{D}^{(\alpha)}\right) \\
-\mathrm{m}_{\alpha}\left[\mathrm{U}_{\alpha}+\left(\mathbf{J}^{(\alpha)}-\frac{1}{2} \mathbf{v}^{(\alpha)}\right) \cdot \mathbf{v}^{(\alpha)}-\mathrm{G}_{\alpha}\right]
\end{array}
$$

Entropy:

$$
\sum_{\alpha}\left[\rho_{\alpha} \frac{\mathrm{D}^{(\alpha)} \mathrm{S}_{\alpha}}{\mathrm{Dt}}+\mathrm{m}_{\alpha} \mathrm{S}_{\alpha}+\operatorname{div}\left(\frac{\mathbf{q}^{(\alpha)}}{\theta_{\alpha}}\right)-\frac{\rho_{\alpha} \mathrm{r}_{\alpha}}{\theta_{\alpha}}\right] \geq 0
$$

where

$$
\begin{aligned}
& \rho \mathbf{v}=\sum_{\alpha} \rho_{\alpha} \mathbf{v}^{(\alpha)} \\
& \frac{\mathrm{D}^{(\alpha)} \beta}{\mathrm{Dt}}=\frac{\partial \beta}{\partial \mathrm{t}}+\mathbf{v}^{(\alpha)} \cdot \operatorname{grad} \beta \\
& \text { (for any scalar } \beta \text { ) }
\end{aligned}
$$




$$
\begin{aligned}
& \frac{\mathrm{D}^{(\alpha)} \mathbf{w}}{\mathrm{Dt}}=\frac{\partial \mathbf{w}}{\partial \mathrm{t}}+(\operatorname{grad} \mathbf{w}) \mathbf{v}^{(\alpha)} \\
& \quad(\text { for any vector } \mathbf{w}) \\
& \sum_{\alpha} \mathrm{m}_{\alpha}=0 ; \quad \sum_{\alpha}\left(\boldsymbol{\pi}^{(\alpha)}+\mathrm{m}_{\alpha} \mathbf{J}^{(\alpha)}\right)=0
\end{aligned}
$$

The entropy inequality becomes:

$$
\sum_{\alpha} \eta_{\alpha} \geq 0
$$

where

$$
\begin{gathered}
\eta_{\alpha}=-\rho_{\alpha} \frac{\mathrm{D}^{(\alpha)} \mathrm{A}_{\alpha}}{\mathrm{Dt}}-\rho_{\alpha} \mathrm{S}_{\alpha} \frac{\mathrm{D}^{(\alpha)} \theta_{\alpha}}{\mathrm{Dt}}-\mathrm{m}_{\alpha}\left[\mathrm{A}_{\alpha}+\left(\mathbf{J}^{(\alpha)}-\frac{1}{2} \mathbf{v}^{(\alpha)}\right) \cdot \mathbf{v}^{(\alpha)}-\mathrm{G}_{\alpha}\right] \\
+\psi_{\alpha}+\operatorname{tr}\left(\mathbf{T}_{\mathrm{s}}^{(\alpha)} \mathbf{D}^{(\alpha)}\right)-\frac{\mathbf{q}^{(\alpha)} \cdot \operatorname{grad} \theta_{\alpha}}{\theta_{\alpha}}
\end{gathered}
$$

In the above equations $\rho$ is the density, $\mathbf{v}$ is the velocity vector, $\mathbf{D}$ is the symmetric part of the velocity gradient, $\mathbf{T}$ is the stress tensor, $\boldsymbol{\pi}$ represents the interaction forces, $\theta$ is the temperature, $U$ is the internal energy, $r$ is the radiant heating, $A_{\alpha}$ is the Helmholtz free energy ( $\left.=\mathrm{U}_{\alpha}-\theta_{\alpha} \mathrm{S}_{\alpha}\right), \mathrm{S}_{\alpha}$ is the entropy per unit mass, and $\mathbf{q}$ is the heat flux vector. Associated with each supply term, one could have a force field also, where $\psi_{\alpha}, \mathrm{m}_{\alpha}$ and $\mathrm{G}_{\alpha}$ are the supply terms. The term $\mathbf{T}_{\mathbf{s}}{ }^{(\alpha)}$ denotes the symmetric part of the partial stress tensor $\mathbf{T}^{(\alpha)}$, and $\boldsymbol{\lambda}^{(\alpha)}$ is an anti-symmetric second order tensor representing an internal body couple. It can be seen from equation 2.9 that, although the total stress tensor of the mixture must be symmetric, the partial stresses need not be. The entropy inequality, which can be reduced to what is called the Clausius-Duhem inequality, can be used to impose certain restrictions on the types of motions and processes that can be allowed so that the entropy law is not violated. It can also yield further insight into the nature and behavior of certain material parameters. For a chemically non-reacting $\left(\mathrm{m}_{\alpha}=0\right)$ mixture, with the same temperature $\theta$, the equations are considerably simplified. Constitutive relations are required for $A_{\alpha}, S_{\alpha}, \pi, \mathbf{q}$, and $\mathbf{T}^{(\alpha)}$. The importance of the interaction forces $\pi$ in multiphase mixtures has been recently reviewed and discussed by Massoudi (2002, 2003).

For a two-component system, the above equations are simplified. The fluid in the mixture will be represented by $S_{1}$ and the particles by $S_{2}$. At each instant of time, $t$, it is assumed that each point in space is occupied by particles belonging to both $S_{1}$ and $S_{2}$. The kinematical quantities associated with these motions are as follows:

$$
\begin{array}{r}
\mathbf{v}_{1}=\frac{\mathrm{D}_{1} \tilde{\chi}_{1}}{\mathrm{Dt}} \quad \mathbf{v}_{2}=\frac{\mathrm{D}_{2} \tilde{\chi}_{2}}{\mathrm{Dt}}, \mathbf{a}_{1}=\frac{\mathrm{D}_{1} \mathbf{v}_{1}}{\mathrm{Dt}}, \quad \mathbf{a}_{2}=\frac{\mathrm{D}_{2} \mathbf{v}_{2}}{\mathrm{Dt}}, \quad \mathbf{L}_{1}=\frac{\partial \mathbf{v}_{1}}{\partial \mathbf{x}_{1}}, \quad \mathbf{L}_{2}=\frac{\partial \mathbf{v}_{2}}{\partial \mathbf{x}_{2}}, \\
\mathbf{W}_{1}=\frac{1}{2}\left(\mathbf{L}_{1}-\mathbf{L}_{1}^{\mathrm{T}}\right), \mathbf{W}_{2}=\frac{1}{2}\left(\mathbf{L}_{2}-\mathbf{L}^{\mathrm{T}}{ }_{2}\right) \mathbf{D}_{1}=\frac{1}{2}\left(\mathbf{L}_{1}+\mathbf{L}_{1}^{\mathrm{T}}\right), \quad \mathbf{D}_{2}=\frac{1}{2}\left(\mathbf{L}_{2}+\mathbf{L}_{2}^{\mathrm{T}}\right),
\end{array}
$$


where the motion of the constituents is represented by the mappings: $\mathbf{x}_{\mathbf{1}}=\tilde{\chi}_{\mathbf{1}}\left(\mathbf{X}_{1}, \mathrm{t}\right)$, and $\mathbf{x}_{\mathbf{2}}=\tilde{\chi}_{\mathbf{2}}\left(\mathbf{X}_{2}, \mathrm{t}\right), \mathbf{v}$ denotes velocity, $\mathbf{a}$ is acceleration, $\mathbf{L}$ is the velocity gradient, $\mathbf{D}$ denotes the symmetric part of the velocity gradient, and $\mathbf{W}$ is the spin tensor. $\mathrm{D}_{1} / \mathrm{Dt}$ denotes differentiation with respect to t, holding $\mathbf{X}_{1}$ fixed, and $\mathrm{D}_{2} / \mathrm{Dt}$ denotes the same operation, holding $\mathbf{X}_{2}$ fixed. Also, $\rho_{1}$ and $\rho_{2}$ are the bulk densities of the mixture components given by $\rho_{1}=\varphi \rho_{\mathrm{f}}, \rho_{2}=v \rho_{\mathrm{s}}$, where $\rho_{\mathrm{f}}$ is the density of the pure fluid, $\rho_{\mathrm{s}}$ is the density of the solid grains, $\varphi$ is the volume fraction of the fluid component, and $v$ is the volume fraction of the solid. For a saturated mixture $\varphi=1-v$. The mixture density $\rho_{\mathrm{m}}$ is given by $\rho_{\mathrm{m}}=\rho_{1}+\rho_{2}$, and the mean velocity $\mathbf{v}_{\mathbf{m}}$ of the mixture is defined by $\rho_{\mathrm{m}} \mathbf{v}_{\mathrm{m}}=\rho_{1} \mathbf{v}_{\mathbf{1}}+\rho_{2} \mathbf{v}_{2} \cdot$ (see Massoudi 2010).

In the continuous casting process of steel making, it is important to understand the behavior and the impact of nonmetallic inclusions and bubbles that accompany the flowing liquid in the casting. Thomas and Zhang (2001) review the various mechanisms that have been used to date. They list the two most popular approaches taken by different researchers according to the specific application: (1) convection-diffusion approach; (2) particle trajectory approach. In the first instance, the particle equation is given by a single transport equation for the volume fraction:

$$
\frac{\partial \sigma_{p}}{\partial t}+u_{i p} \frac{\partial \sigma_{p}}{\partial x_{i}}=\frac{\partial}{\partial x_{i}}\left(D_{\text {eff }} \frac{\partial \sigma_{p}}{\partial x_{i}}\right)
$$

where $\sigma_{p}$ is the volume fraction of the particle (or the inclusion), $u_{i p}$ is the particle velocity, $\mathrm{D}_{\text {eff }}$ is the effective diffusion coefficient. For the latter example, they suggest using the Lagrangian approach where the equation of motion is usually given by some type of BBO equation (see Massoudi 2002). However, the specific equation that they used is not fame-indifferent; that is, it violates the principle of Objectivity (see Truesdell and Noll 1992). Thomas and Zhang suggested the following equation:

$$
\frac{d v_{p i}}{d t}=-\frac{3}{4} \frac{C_{D} v_{P i} \rho}{d_{p} \rho_{p}}\left|v_{p i}-u_{i}\right|+\frac{\left(\rho_{p}-\rho\right) g}{\rho_{p}}+C_{A}\left(\frac{d u_{i}}{d t}-\frac{d v_{P i}}{d t}\right)
$$

It is basically the last term on the right hand side, the relative acceleration term (often referred to as the virtual mass) which is not frame-invariant. In the above equation, $\rho_{p}$ and $\rho$ are the particle and liquid densities, $v_{p i}$ is the particle velocity, $C_{D}$ is the drag coefficient, which is a function of the particle Reynolds number, and $\mathrm{C}_{\mathrm{A}}$ is a constant related to the added mass effect. They also suggested that the effect of turbulence can be modeled using a $\mathrm{K}-\varepsilon$ equation. Thomas and Zhang (2001) recommend that at times it is more suitable to use a two-phase model or the Eulerian approach.

In the next section, we discuss the various approaches taken by different researchers in formulating or obtaining a slag viscosity model. In general, these models are based on experiments. 


\section{THE IMPORTANCE OF SLAG LAYER VISCOSITY IN GASIFICATION AND COMBUSTION PROCESSES}

\subsection{Viscosity of Slags}

Studies have indicated that slag viscosity must be within a certain range of temperatures for tapping and for the membrane wall to be accessible, for example, between $1300{ }^{\circ} \mathrm{C}$ and $1500{ }^{\circ} \mathrm{C}$, the viscosity is approximately $25 \mathrm{~Pa} \cdot \mathrm{s}$ (see Browning et al., ( 2003). In one of the earliest studies, Bills (1963) reported that the addition of calcium fluoride leads to a lowering of the slag viscosity. In the blast furnace slag system, the impact of $\mathrm{MgO}$ on the viscosity of slag is of interest. Kim et al., (2010) used the rotating spindle connected to a Brookfield digital viscometer to measure the viscosity of slag containing $\mathrm{MgO}$ at high concentrations of $\mathrm{Al}_{2} \mathrm{O}_{3}$, while $\mathrm{Xu}$ et al. (2011) used an RTW-08 type testing instrument to measure the viscosity of $\mathrm{CaO}-\mathrm{Al}_{2} \mathrm{O}_{3}-\mathrm{MgO}$ slag systems. It is interesting that fluxing compounds such as calcium oxide, which are added to coals primarily to reduce the slag viscosity, play a similar role as polymeric additives, which are added to many fluids to reduce the drag.

As the operating temperature decreases, the slag cools, and solid crystals begin to form. In such cases, the slag should be regarded as a non-Newtonian suspension, consisting of liquid silicate and crystals (Vargas et al., (2001). In such cases, a better understanding of the rheological properties of the slag, such as yield stress and shearthinning, are critical in determining the optimum operating conditions. Groen et al., (1998) observed that, in slags where titanium-rich feeds are used, the melting point is lowered up to $27.5 \%$, and, where calcium-rich feeds are used, there is an increase in the glass fluidity for $\mathrm{CaO}$ contents up to $30 \%$, regardless of the amount of titanium present in the feed. They noticed that at the critical viscosity temperature, $T_{c v}$, the slag changes from a homogeneous fluid to a mixture composed of fluid and a crystallizing phase (solid), where there is an increase in the (apparent) viscosity due to the presence of the crystals or the change in the melt composition. Kong et al., (2011) observed that adding pulverized limestone with the effective ingredient of $\mathrm{CaO}$ improves slag flow properties. They also noticed that, at the temperatures below the temperature of critical viscosity, referred to in their analysis as $T_{c v}$, the slag behavior is non-Newtonian. Stanmore and Budd (1996) point out that ashes formed in the 0.1-10 MPa s range, which are generally at temperatures above $1000{ }^{\circ} \mathrm{C}$ (assumed normally to behave as Newtonian fluids), are in fact very likely to be two- or multi-phase mixtures. They indicated that both yield stress and yield viscosity (Bingham viscosity) depend on temperature. They used the squeeze film rheometer to measure the viscosity. For a detailed analysis of using the programmable Brookfield LVDV-II+ viscometer and how it can be used to measure the viscosities of slag with fluxes, see Forsbacka et al., (2003). For using the rotating crucible viscometer to measure the viscosity of blast furnace type slags, we refer the reader to Saito et al., (2003). Pandey et al (2011) presented a novel technique, whereby they attempted to measure the properties of mould powder slags, such as viscosity, liquidus temperature, etc., using ultrasonics.

According to Seetharaman et al., (2005), most slags are ionic in nature. Their viscosities are very sensitive to the size of the ions and the electrostatic interactions, and, as more and more basic oxides are added to pure silica, the silicate network breaks down, 
and viscosity begins to decrease gradually. In addition to discussing the traditional methods of measuring slag viscosity, Seetharaman et al., (2005) mention two other related concepts: the surface dilatational viscosity and the two-phase viscosity. They suggest that surface dilatational viscosity, although very difficult to measure at high temperatures, is an important quantity to be considered especially when foaming, coalescing bubbles, dispersion of droplets or solid particles, etc. For the two-phase viscosity, they suggest using the two well-known equations for viscosity based on the works of Einstein (1956) and the later contribution by Taylor (1932) (see also Batchleor 1976).

In general, the feedstock for a given gasification process may include coal, heavy oil, coke, and wastes such as sewage sludge, biomass or even scrap tire. The gasification of petroleum coke is receiving more attention because of its heating value and low cost, while pressing special challenges due to its composition: vanadium, nickel, and iron. Park and Oh (2008) studied the viscosity of Korean anthracite slag, which contains a large portion of vanadium trioxide $\left(\mathrm{V}_{2} \mathrm{O}_{3}\right)$. They observed that, in order to keep the slag flowing, the temperature had to be kept above $1670{ }^{\circ} \mathrm{C}$, which is $270{ }^{\circ} \mathrm{C}$ above the typical operating temperature for slurry-feed gasifiers. Based on their experimental results, they suggested two optimum ranges for gasification, namely glassy slag and crystalline slag.

To a certain extent, magnesia raises the viscosity of slags while increasing the liquidus temperature. However, as Ducret and Rankin (2002) observed, above a certain concentration, MgO increases the viscosity. They also reference a study performed by Broadbent et al. (1992), in which 13 reputable laboratories measured the viscosity of the same synthetic slag and obtained varied variation around the mean by as much as $50 \%$. As pointed out by Sridhar (2002), slags and fluxes are commonly used in many of the iron and steel or copper making and refining industries, as well as aluminum melting. In these applications, slags provide a protection layer for the molten metal surface from the atmosphere, while absorbing the impurities during the casting and creating some lubrication between the mold and metal strand, etc. The most important parameter in all these cases is the slag viscosity. Sridhar (2002) provides an excellent summary of a few important models for the viscosity of slags.

Patterson and Hurst (2000) presented slag viscosity as a function of temperature for different kinds of Australian coal. When necessary they used limestone to lower the liquidus temperature and slag viscosity for optimum operation and slag tapping. Tonmukayakul and Nguyen (2002) state that traditional methods for viscosity measurements and instrumentation might be satisfactory for coal ash slags obtained from bituminous (black) coal or those with high silica content but inaccurate for the cases with lower temperatures, where the coal may be partially molten and generally behaves as a non-Newtonian fluid. To overcome this problem, they suggested using a cone and plate rheometer, in which a volume of molten ash contained between a thin gap and a plate at a small cone angle is sheared. Although they do not provide any equations, other than to state that an Arrhenius-type equation satisfactorily represents the effects of temperature for both ash samples, this study is a valuable example of how careful measurements can provide a good deal of information for modeling purposes. For example, they observed that between 1150 and $1300{ }^{\circ} \mathrm{C}$, the data of shear stress versus shear rate for melt as a function of temperature indicate that the oxide melt behaves as a Newtonian fluid; however, in the temperature ranges from 850 to $1200{ }^{\circ} \mathrm{C}$, coal ash was shown to have a 
non-linear response, thus exhibiting non-Newtonian characteristics. Specifically, and more importantly, they mention that this ash sample (the Loy Yang coal) should be modeled as viscoplastic shear-thinning fluid with a yield stress. They conclude that the presence of a high yield stress for the slag, in the range of operating temperatures, confirm previous findings (see Tonmukayakul and Nguyen 2002) that a high alkali sulphate ash is more likely to agglomerate in fluidized-bed combustion than a silica rich coal.

Song et al., (2010) devised a high-temperature rheometer to study the rheological characteristics of slag, specifically the thixotropy and yield stress at different temperatures ranging from 500 to $1550{ }^{\circ} \mathrm{C}$. Although they did not provide any equations, their results presented in graphical forms indicate that the slags behave as a thixotropic shear-thinning non-Newtonian fluid with a yield stress. Measuring yield stress is very difficult, even under normal conditions, let alone under such high temperatures. Like other researchers, Song et al. extrapolated the straight-line section of the data in the shear-rate vs. shear-stress curve to obtain the value of the yield stress. They also observed that the shear-thinning became more distinct as the temperature decreased.

\subsection{A Brief Review of Various Viscosity Models}

Watt and Fereday (1969) presented one of the earliest and most comprehensive studies of the measurement of viscosity of slags using British coals and the rotating cylinder-type viscometer. Melted ash was poured into a crucible at a temperature between $1700-1800{ }^{\circ} \mathrm{C}$ and maintained at this temperature until the value of obtained viscosity had remained constant for an hour. Using an Arrhenius type equation, they related viscosities of slags for the entire temperature range to their compositions expressed in terms of the percent by weight of $\mathrm{SiO}_{2}, \mathrm{Al}_{2} \mathrm{O}_{3}, \mathrm{MgO}, \mathrm{CaO}$, and iron oxides, where

$$
\eta=A \exp \left(\frac{E}{R T}\right)
$$

was changed into

$$
\log \eta(\text { in poise })=\frac{10^{7} \mathrm{~m}}{(\mathrm{t}-150)^{2}}+\mathrm{c}
$$

where $\mathrm{m}$ and c are given in terms of compositions and $\mathrm{t}$ is the temperature in degrees $\mathrm{C}$, where

$$
\begin{aligned}
& \mathrm{m}=0.0083 \mathrm{SiO}_{2}+0.00601 \mathrm{Al}_{2} \mathrm{O}_{3}-0.109 \\
& \mathrm{c}=0.0415 \mathrm{SiO}_{2}+0.0192 \mathrm{Al}_{2} \mathrm{O}_{3}+0.0276 \text { Equiv } \mathrm{Fe}_{2} \mathrm{O}_{3}+0.0160 \mathrm{CaO}-3.92 \\
& \mathrm{SiO}_{2}+\mathrm{Al}_{2} \mathrm{O}_{3}+\text { Equiv } \mathrm{Fe}_{2} \mathrm{O}_{3}+\mathrm{CaO}+\mathrm{MgO}=100(\mathrm{wt} \%)
\end{aligned}
$$

They also compared their results with the so-called $S^{2}$ formula (Hoy et al., (1965), in which viscosity is given by the following equation: 


$$
\log \eta=4.468\left(\frac{S}{100}\right)^{2}+1.265\left(\frac{10^{4}}{\mathrm{~T}}\right)-7.44
$$

where $\mathrm{S}$ is the silica ratio and $\mathrm{T}$ is the temperature given in degrees $\mathrm{K}$. It was shown that the new correlation provides better comparison with the data.

Kato and Minowa (1969) measured the viscosity of slag composed of $\mathrm{CaO}-\mathrm{SiO}_{2}-\mathrm{Al}_{2} \mathrm{O}_{3}$. The effects of various other additions were also considered. They used a balanced platinum sphere viscometer and suggested the following equation:

$$
\eta=\mathrm{KW}\left(\mathrm{t}_{1}-\mathrm{t}_{2}\right)
$$

where $\mathrm{K}$ is constant related to the apparatus, $\mathrm{W}$ is the weight necessary to raise the sphere through the slag, $t_{\mathbf{1}}$ is the time necessary to raise the sphere for $10 \mathrm{~mm}$ in the slag, and $t_{2}$ is the time required to raise the sphere in air $10 \mathrm{~mm}$. The temperature dependence of the viscosity was expressed by an Arrhenius-type equation, also known as the Andrade's equation:

$$
\eta=A_{\eta} \exp \left(\frac{E_{\eta}}{R T}\right)
$$

where $A_{\eta}$ is a frequency factor, $E_{\eta}$ is the activation energy, $\mathrm{R}$ is the gas constant, and $\mathrm{T}$ is the absolute temperature. It was observed that the value of $E_{\eta}$ increases with $\mathrm{Al}_{2} \mathrm{O}_{3}$ or $\mathrm{SiO}_{2}$ content, and that the slag is more viscous perhaps due to network formation. Overall, they found out that the viscosity coefficient and the activation energy of this molten slag increased with the increasing amount of $\mathrm{Al}_{2} \mathrm{O}_{3}$ or $\mathrm{SiO}_{2}$ while $\mathrm{CaO}$ lowered these values. Furthermore, it was observed that the addition of $\mathrm{FeO}, \mathrm{MnO}$, or $\mathrm{MgO}$, which are popular in steel-making, lowered the viscosity but increased the activation energy.

Perhaps the most widely used equation for the viscosity of slag is that of Urbain (1987) who used basic ideas from statistical and molecular physics to relate the fluidity (the inverse of viscosity) to two probabilities related to the variable of the state and to the structure of the liquid (a measure of polymerization). He deduced that one of these probabilities, $\mathrm{P}_{\mathrm{e}}$, is related to the energy level of the potential. Urbain therefore used a statistical approach suggested by Weymann (1962) to obtain an exponential-type equation for the viscosity. For the other probability, $\mathrm{P}_{\mathrm{v}}$, denoted as the 'hole' probability, Urbain suggested that it is proportional to the concentration of the 'holes' given at $\mathrm{T}$ via another exponential function. By combining these two functions, Urbain suggested a twoparameter expression for the viscosity:

$$
\mu=\mathrm{AT} \exp (1000 \mathrm{~B} / \mathrm{T})
$$

where $A$ is a function of various parameters such as mass, volume of the structural unit, the energy of the well, and the partial molar entropy, and B is a function of the energy of the well and the partial molar enthalpy. Urbain showed that A and B are related through

$$
\ln A=\ln A_{0}+E /\left(R T_{c}\right)-1000 B / T_{c}
$$


where $\mathrm{A}_{0}, \mathrm{E}$ and $\mathrm{T}_{\mathrm{c}}$ are constants for a given liquid; this equation can be generalized to

$$
-\ln \mathrm{A}=\mathrm{mB}+\mathrm{n}
$$

where $\mathrm{m}$ and $\mathrm{n}$ are obtained from experimental data. For a group of 54 liquids, Urbain suggested the mean values of these two parameters to be:

$$
\begin{aligned}
& m=0.29 \\
& n=11.57
\end{aligned}
$$

The above model has been generalized by various authors for different conditions.

Riboud et al., (1987) suggested that parameters A and B in the Urbain model should be polynomial functions of the composition. Kondratiev and Jak (2001) used a similar argument and suggested that parameters $\mathrm{m}$ and $\mathrm{n}$ should also be functions of composition in the following manner:

$$
\mathrm{m}=\mathrm{m}_{\mathrm{A}} \mathrm{X}_{\mathrm{A}}+\mathrm{m}_{\mathrm{C}} \mathrm{X}_{\mathrm{C}}+\mathrm{m}_{\mathrm{F}} \mathrm{X}_{\mathrm{F}}+\mathrm{m}_{\mathrm{S}} \mathrm{X}_{\mathrm{S}}
$$

where the m's are model parameters and the X's are the molar fractions of $\mathrm{Al}_{2} \mathrm{O}_{3}-\mathrm{CaO}$ ' $\mathrm{FeO}$ '- $\mathrm{SiO}_{2}$ respectively. They obtained the optimized values of the $\mathrm{m}$ 's by fitting the experimental values of $\mathrm{A}$ and $\mathrm{B}$. Building on the previous modifications to the Urbain model, Kondratiev and Jak (2001) suggested two different continuous functions for B for two different modifiers ( $\mathrm{FeO}$ and $\mathrm{CaO}$ ):

$$
\begin{aligned}
& \mathrm{B}=\sum_{\mathrm{i}=0}^{3} \mathrm{~b}_{\mathrm{i}}^{0} \mathrm{X}_{\mathrm{S}}^{\mathrm{i}}+\sum_{\mathrm{i}-0}^{3} \sum_{\mathrm{j}=1}^{2}\left(\mathrm{~b}_{\mathrm{i}}^{\mathrm{Cj}} \frac{\mathrm{X}_{\mathrm{C}}}{\mathrm{X}_{\mathrm{C}}+\mathrm{X}_{\mathrm{F}}}+\mathrm{b}_{\mathrm{i}}^{\mathrm{Fj}} \frac{\mathrm{X}_{\mathrm{F}}}{\mathrm{X}_{\mathrm{C}}+\mathrm{X}_{\mathrm{F}}}\right) \alpha^{\mathrm{j}} \mathrm{X}_{\mathrm{S}}^{\mathrm{i}} \\
& \alpha=\frac{\mathrm{X}_{\mathrm{C}}+\mathrm{X}_{\mathrm{F}}}{\mathrm{X}_{\mathrm{C}}+\mathrm{X}_{\mathrm{F}}+\mathrm{X}_{\mathrm{A}}}
\end{aligned}
$$

where $b_{i}^{0}$ values are parameters for the $\mathrm{Al}_{2} \mathrm{O}_{3}-\mathrm{SiO}_{2}$ system, while $b_{i}^{\mathrm{Cj}}, b_{i}^{\mathrm{Fj}}$ are parameters for $\mathrm{CaO}$-'FeO' system, all obtained by optimization.

Generally, the temperature of critical viscosity, $T_{c v}$, is defined as the temperature where the behavior of the molten ash, specifically its viscosity, changes from a Newtonian fluid to that of a non-Newtonian fluid, specifically a Bingham fluid (see Nowok 1994, 1995). At this temperature, coal ash undergoes phase transformation, which can be due to nucleation and crystal growth, phase separation, etc. Nowok (1994) suggested that the viscosity of slag near the $\mathrm{T}_{\mathrm{cv}}$ depends on the well known second order equation, in which viscosity is related to the volume faction of the solid particles:

$$
\eta_{\text {mix }}=\eta_{\mathrm{r}}\left(1+\mathrm{c} \phi+\mathrm{d} \phi^{2}\right)
$$

where $\mathrm{c}$ and $\mathrm{d}$ are constants related to the shape of the dispersants and solid-melt interaction, $\phi$ is the volume fraction, and $\eta_{r}$ is the viscosity of the 'residual slag'. It is suggested that a sudden increase in viscosity is due to a phase transformation, which results from both a nucleation and a spinodal decomposition. 
Another interesting entrained flow gasifier is the Prenflo, which operates at temperatures above ash slagging, where the molten ash accumulates at the inside walls of the gasifier, due to centrifugal forces. Between the liquid layer and the cold walls a solid slag layer is formed (see Seggiani 1998). Reid and Cohen (1944) suggested that the molten slag behaves as a Newtonian fluid above the critical temperature viscosity, $T_{c v}$, and as a plastic fluid below $T_{c v}$, while Johnson (1984) assumed that molten ash behaves as a Bingham fluid over the entire range of temperatures considered. Seggiani (1998) used the relative amounts of the basic and acidic constituents in the slag to predict the $T_{c v}$ and the slag viscosity; he also indicated that specific heat and thermal conductivity are important transport quantities that need to be studied. Specifically, he suggested the following correlation for $T_{c v}$ as a function of the acid/base ratio:

$$
\mathrm{A} / \mathrm{B}=\frac{\mathrm{SiO}_{2}+\mathrm{Al}_{2} \mathrm{O}_{3}+\mathrm{TiO}_{2}}{\mathrm{Fe}_{2} \mathrm{O}_{3}+\mathrm{CaO}+\mathrm{MgO}+\mathrm{Na}_{2} \mathrm{O}+\mathrm{K}_{2} \mathrm{O}}
$$

where the slag components are given in weight percentages. Based on a linear regression, the $\mathrm{T}_{\mathrm{Cv}}$ was given as

$$
\mathrm{T}_{\mathrm{cv}}=1385.44+74.1(\mathrm{~A} / \mathrm{B}) \quad(\mathrm{K})
$$

and

$$
\log \eta=4.468 S^{2}+1.265\left(\frac{10^{4}}{\mathrm{~T}}\right)-7.44
$$

which is valid above the $T_{c v}$, where $\eta$ is the viscosity in poise, $\mathrm{S}$ is the silica ratio, and $\mathrm{T}$ is the temperature given in degrees $\mathrm{K}$.

Hurst et al., (1999) used a Haake high-temperature rotational viscometer with molybdenum and crucibles to measure viscosity of various slags. Similar to other researchers before them, they presented in contour plots the viscosity and the $T_{c v}$ of slags composed of $5 \%$ and $10 \%$ FeO. They used a modified Urbain model where the coefficients in the polynomial functions depend on the composition. To calculate viscosity, they suggested the following equation, based on a least squares fit of the experimental data, for the temperature range of $1400-1500{ }^{\circ} \mathrm{C}$,

$$
-\ln \eta=A+\frac{B}{T}
$$

where A and B are given in tabular forms and their values are different for each slag. For the experimental treatment of the data, Hurst et al., (1999) used a modified Urbain model using the Weyman equation: 


$$
\begin{aligned}
& \eta=A+\exp \left(\frac{B}{R T}\right) \\
& \text { or } \\
& \ln \eta=\ln A+\ln T+\frac{B}{R T} \\
& =a_{0}+a_{1} y+a_{2} y^{2}+a_{3} x+a_{4} x y+a_{5} x^{2}+a_{6} x^{2}+a_{7} x^{2} y \\
& +a_{8} x^{2} y^{2}+a_{9} x^{3}+a_{10} x^{3} y+a_{11} x^{3} y^{2}
\end{aligned}
$$

where $\mathrm{R}$ is the gas constant and $\mathrm{x}$ and $\mathrm{y}$ are the normalized mole fractions given by

$$
\begin{aligned}
& \mathrm{x}=\frac{\mathrm{m}_{\mathrm{s}}}{\mathrm{m}_{\mathrm{s}}+\mathrm{m}_{\mathrm{a}}+\mathrm{m}_{\mathrm{c}}+\mathrm{m}_{\mathrm{f}}} \\
& \mathrm{y}=\frac{\mathrm{m}_{\mathrm{c}}+\mathrm{m}_{\mathrm{f}}}{\mathrm{m}_{\mathrm{a}}+\mathrm{m}_{\mathrm{c}}+\mathrm{m}_{\mathrm{f}}}
\end{aligned}
$$

This study was specifically aimed at the $\mathrm{SiO}_{2}-\mathrm{Al}_{2} \mathrm{O}_{3}-\mathrm{CaO}-\mathrm{FeO}$ (SACF) system at 5 and $10 \%$ wt FeO. Later, Hurst et al., (2000) extended this study to include synthetic slags at the $15 \%$ wt $\mathrm{FeO}$; they obtained similar results.

Mills and Sridhar (1999) also extended the Urbain model by making A and B functions of a correction factor, related to optical basicity, denoted by $\Lambda^{\text {corr }}$. They called this model the National Physical Laboratory (NPR) model and, specifically, they suggested the following correlations, which are based on experimental data:

$$
\begin{aligned}
& \frac{\ln B}{1000}=-1.77+\frac{2.88}{\Lambda^{\text {corr }}} \\
& \ln A=-232.69\left(\Lambda^{\text {corr }}\right)^{2}+357.32 \Lambda^{\text {corr }}-144.17
\end{aligned}
$$

Iida et al., (2000) suggested a viscosity model where the effects of the slag through the (network) structure is taken into account by the basicity of slag. Thus,

$$
\mu=\mu_{0} A \exp \left(\frac{E}{\mathrm{Bi}^{*}}\right)
$$

where

$$
\begin{aligned}
& \mathrm{A}=1.745-1.962 \times 10^{-3} \mathrm{~T}+7 \times 10^{-7} \mathrm{~T}^{2} \\
& \mathrm{E}=11.11-3.65 \times 10^{-3} \mathrm{~T}
\end{aligned}
$$

where $\mathrm{A}$ and $\mathrm{E}$ are parameters to be fitted from the experimental data, and $\mu_{0}$ is the hypothetical viscosity of the non-networking slag expressed as a complicated exponential function, which depends on many parameters such as the molar volume at the melting temperature, the gas constant, the mole fraction, etc. The modified 'basicity' index $\mathrm{Bi}^{*}$ was calculated from another complicated function that depends on many parameters, 
especially on the mass percentage of the various components present in the slag, for example, $\mathrm{CaO}-\mathrm{SiO}_{2}-\mathrm{Al}_{2} \mathrm{O}_{3}-\mathrm{MgO}$, etc.

Reddy and Hebbar (2001), based on the works of Bockris and Reddy (1970) and Reddy and Hebbar (1991), suggested the following equation for the viscosity of slag:

$$
\eta=4.9 \times 10^{-10} \mathrm{~N}_{\mathrm{O}}^{0} \mathrm{~T}^{1 / 2} \exp \left(\frac{\mathrm{E}}{\mathrm{RT}}\right)
$$

Where the $\mathrm{N}_{\mathrm{O}}^{0}$ value takes into account the depolymerization and subsequent breakdown of the silicate network structure, and $\mathrm{E}$ is the energy needed to break the bond, given by a polynomial function

$$
\mathrm{E}=\alpha+\beta \mathrm{N}_{\mathrm{O}}^{0}+\gamma\left(\mathrm{N}_{\mathrm{O}}^{0}\right)^{2}+\delta\left(\mathrm{N}_{\mathrm{O}}^{0}\right)^{3}+\varepsilon\left(\mathrm{N}_{\mathrm{O}}^{0}\right)^{4}
$$

where $\alpha, \beta, \gamma, \varepsilon$ are functions of temperature given by experimental correlations in the polynomial form.

It is known that in IGCC slagging gasifiers, the (coal ash) slags should be 'fluid' enough to be tapped. However, in many cases, the IGCC processes operate at conditions where there are still some solid particles in the liquid phase, and therefore, a complete understanding of the rheological behavior of slag should allow for the case of "partly crystallized slag," which contains some solid particles. Kondratiev and Jak (2001) developed a viscosity model for the cases of completely liquid and heterogeneous and partly crystallized, using a semi-empirical model originally introduced by Urbain et al., (1981) for $\mathrm{Al}_{2} \mathrm{O}_{3}-\mathrm{CaO}-\mathrm{FeO}^{\prime}-\mathrm{SiO}_{2}$ systems in equilibrium with metallic iron. Here, the viscosity of the liquid slag was described by the Weymann-Frenkel equation:

$$
\eta_{\mathrm{L}}=\operatorname{AT} \exp \left(\frac{10^{3} \mathrm{~B}}{\mathrm{~T}}\right)
$$

where $\mathrm{T}$ is the temperature in degrees Kelvin. A and $\mathrm{B}$ are model parameters, depending on the liquid composition, related to each other by

$$
-\ln \mathrm{A}=\mathrm{mB}+\mathrm{n}
$$

where $\mathrm{m}$ and $\mathrm{n}$ are model parameters. They represent $\mathrm{B}$ as a polynomial function depending on the slag composition, composed of the three groups: G-glass formation $\left(\mathrm{SiO}_{2}\right)$, Amphamphoteric oxides $\left(\mathrm{Al}_{2} \mathrm{O}_{3}\right)$, and Mod-modifier oxides (CaO-'FeO', MgO), such that

$$
\mathrm{B}=\mathrm{B}_{0}+\mathrm{B}_{1} \mathrm{X}_{\mathrm{G}}+\mathrm{B}_{2} \mathrm{X}_{\mathrm{G}}^{2}+\mathrm{B}_{3} \mathrm{X}_{\mathrm{G}}^{3}
$$


where

$$
\begin{aligned}
& \mathrm{B}_{\mathrm{i}}=\mathrm{b}_{\mathrm{i}}^{0}+\mathrm{b}_{\mathrm{i}}^{1} \alpha+\mathrm{b}_{\mathrm{i}}^{2} \alpha^{2} \\
& \mathrm{i}=0,1,2,3 \text { and } \alpha=\frac{\mathrm{X}_{\mathrm{Mod}}}{\mathrm{X}_{\mathrm{Mod}}+\mathrm{X}_{\mathrm{Amph}}}
\end{aligned}
$$

where $\mathrm{X}_{\mathrm{G}}, \mathrm{X}_{\mathrm{Mod}}$ and $\mathrm{X}_{\mathrm{Amph}}$ are the mole fractions of glass formers, modifiers, and amphoteric oxides, respectively. Kondratiev and Jak (2001) also tested a number of viscosity correlations for the heterogeneous liquids and found that the Roscoe equation (see Roscoe 1952) is suitable for the cases studied. This equation is appropriate for a colloidal fluid with suspension of rigid spheres of diverse sizes:

$$
\eta_{\mathrm{S}}=\eta_{\mathrm{L}}\left(1-\mathrm{V}_{\mathrm{S}}\right)^{-2.5}
$$

where $\eta_{s}$ is the viscosity of slurry and $V_{s}$ is the volume fraction of solid particles. In this equation, the effects of particle size or shapes are ignored, and it is assumed that the slurry behaves as a Newtonian fluid whose viscosity is given by this equation. According to the experimental results of Wright et al. (2000), Roscoe's equation can be used for partly crystallized slags.

Shahbazian (2001) reported that the viscosity of slag depends strongly on the size of the silicate anions by observing the viscosity variation with basicity (the ratio of $\frac{\mathrm{CaO}+\mathrm{FeO}}{\mathrm{SiO}_{2}}$ ), where a sharp decrease in viscosity in the basicity region 1 to 1.4 was seen.

Mudersbach et al., (2001) also generalized the Urbain model by adjusting the coefficients of Weymann's temperature relation to depend on the $\mathrm{CaO} / \mathrm{SiO}_{2}$ basicity of the slag, namely

$$
\eta=A T \exp \left(\frac{10^{3} B}{T}\right)
$$

where

$$
\begin{aligned}
& A=f(C / S-\text { basicity }) ; \\
& B=f\left(X_{\text {oxides }}\right)
\end{aligned}
$$

Thus, in this model, referred to as the FEhS model, $\mathrm{m}$ and $\mathrm{n}$ are adjusted to include the effects of the $\mathrm{CaO} / \mathrm{SiO}_{2}$ basicity.

Browning et al., (2003) provide a brief review of the various slag viscosity models, and they observed that the Kamanovitch-Urbain method is the most accurate for $\mathrm{SiO}_{2}-\mathrm{Al}_{2} \mathrm{O}_{3}-\mathrm{CaO}-\mathrm{MgO}$ slags. They also suggested an empirical method to obtain the viscosity of the slag that depends on finding the temperature shift, among other parameters. For the standard viscosity curve they suggested the following expression:

$$
\log \left(\frac{\eta}{T-T_{s}}\right)=\frac{14788}{T-T_{s}}-10.931
$$


Thus, if the temperature shift for a given slag composition is known, the above equation can be used to find the viscosity above the $T_{c v}$. They also observed that the temperature shift depends on a weighted molar ratio A, given by the following expression:

$$
\mathrm{T}_{\mathrm{s}}=306.63 \ln \mathrm{A}-574.31
$$

where A was given by a polynomial expression in which the coefficients or the quantities associated with each component are in terms of the mole fraction. The idea of the temperature shift is based on the observation made by Nicholls and Reid (1940) who observed that, at a given viscosity, the gradient of the viscosity-temperature curve is the same as if the coal ash slag is in the Newtonian range.

Inaba and Kimura (2004) measured the viscosity of carbon-bearing iron oxide pellets with the acid component of slag by using the oscillating-plate viscometer developed by Iida et al. (2000). Specifically, they used the following equation:

$$
\rho \mu=K\left(\frac{E_{a}}{E}-1\right)^{2}
$$

where

$$
\mathrm{K}=\frac{\mathrm{R}_{\mathrm{M}}^{2}}{\pi \mathrm{f}_{\mathrm{a}} \mathrm{A}^{2}}
$$

where $\rho$ is the density $(\mathrm{kg} / \mathrm{m} 3), \mu$ is the viscosity (Pa.s), $\mathrm{E}_{\mathrm{a}}$ is the amplitude of vibration in the air (m), $\mathrm{E}$ is amplitude of vibration in the liquid, $\mathrm{R}_{\mathrm{M}}$ the impedance of the viscometer $(\mathrm{kg} \cdot \mathrm{m} / \mathrm{s}), \mathrm{f}_{\mathrm{a}}$ is the sympathetic frequency in the air $(\mathrm{Hz})$, and $\mathrm{A}$ is the surface area of both sides of the oscillating plate (m2). The exponent 2 was found not to change with different experiments.

Nakamoto et al (2005) attempted to develop a viscosity model that is non-linear in the concentration of slags. Specifically, they used the concept of "cutting-off" points, which are adjacent to non-bridging oxygen and the free oxygen ions, creating a nonlinear network structure. They suggested that the viscosity of the molten slag depends on the frequency of the occurrence of "cutting-off" points and suggested the following Arrhenius-type equation:

$$
\eta=A \exp \left(\frac{E_{V}}{R T}\right)
$$

where $A$ is a constant and $E_{V}$ is the activation energy for viscosity, which was assumed to be inversely proportional to the distance $\mathrm{S}$, in which the "cutting-off" point moves when a stress is applied. Thus,

$$
E_{V}=\frac{E^{\prime}}{S}
$$

They suggested that for multi-component systems, the activation energy $E_{V}$ is given by

$$
E_{V}=\frac{E}{1+\left(\alpha_{m}\right)^{1 / 2}}
$$


where $\alpha_{\mathrm{m}}$ is given by a complicated equation as a function of the number of oxides, the fractions of the non-bridging oxygen, and the free oxygen ions.

Buhre et al., (2005) discuss the method of thermomechanical analysis (TMA) to determine the slag viscosity. In this method, measurements can be made up to $2400{ }^{\circ} \mathrm{C}$. They showed that

$$
\mu=\frac{\operatorname{mg}}{4 \pi \mathrm{u}\left(\mathrm{L}_{0}+\mathrm{d}\right)}\left[\frac{\ln (1 / \kappa)\left(1+\kappa^{2}\right)-\left(1-\kappa^{2}\right)}{\kappa^{2}}\right]
$$

where $\kappa$ is the ratio of the radius of the ram to the internal radius of the crucible, $\mathrm{R}$ is the internal radius of the crucible (in meters), $u$ is the velocity of the $\mathrm{ram}(\mathrm{m} / \mathrm{s}), \mathrm{L}_{0}$ is the initial length of the annular region, $d$ is the displacement of the ram, $m$ is the mass applied to the rim $(\mathrm{kg})$, and $\mathrm{g}$ is the gravity $\left(\mathrm{kg} / \mathrm{m}^{3}\right)$. The above relationship is the balance between the pressure applied to the ram and the flow rate. Buhre et al., (2005) emphasize that their results are not valid for the cases in which the molten ash contains solids and, thus, behave as a non-Newtonian fluid.

As Seok et al., (2007) observed, the highly basic BOF slags exhibit much higher viscosities than those measured for normal slags. They suggested using the EinsteinRoscoe equation for the liquid melt containing solid particles:

$$
\eta=\eta_{0}(1-\mathrm{af})^{-\mathrm{n}}
$$

where $\eta, \eta_{0}$, and $f$ are the viscosity of the liquid melt with solid particles, without solid particles, and the volume fraction of the particles, respectively. The parameter a is related to the inverse maximum faction of the particles, and the constant $n$ is related to the geometrical shape of the particles and is assumed to be 2.5 for spherical particles.

Kalicka et al., (2009) extended Iida's model for the case of $\mathrm{CaF}_{2}$ and observed that the presence of this component decreased the slag viscosity strongly.

The conventional ash flow temperature (AFT) analysis only takes into account the bulk chemical composition of the mineral phase; that is, the compositions in the slagliquid phase are not distinguished from those in the crystallized phase. The AFT is the main parameter that suggests the suitability of a coal type for combustion or gasification and was originally developed to study the clinker forming characteristics of ash in stokerfired furnaces (see Van Dyk et al., 2009a). Van Dyk et al., (2009a) identified two important temperature ranges: (a) between 900 and $1000^{\circ} \mathrm{C}$, the slag begins to form; and (b) between 1000 and $1250{ }^{\circ} \mathrm{C}$, there is a mixture of slag-liquid and crystallized material. They used the modified "Urbain Model" to calculate the viscosities if various slags:

$$
\ln \eta=\ln A+\ln T+\frac{1000 B}{T}
$$

where

$$
\ln A=-(.2812 B+11.8279)
$$


and

$$
\mathrm{B}=\mathrm{B}_{0}+\mathrm{B}_{1} \mathrm{SiO}_{2}+\mathrm{B}_{2}\left(\mathrm{SiO}_{2}\right)^{2}+\mathrm{B}_{3}\left(\mathrm{SiO}_{2}\right)^{3}
$$

where the B's are given polynomial functions of $\alpha$ where

$\alpha=\frac{\mathrm{M}}{\mathrm{M}+\mathrm{Al}_{2} \mathrm{O}_{3}}$ mole fraction

and

$\mathrm{M}=\mathrm{CaO}+\mathrm{MgO}+\mathrm{Na}_{2} \mathrm{O}+\mathrm{K}_{2} \mathrm{O}+\mathrm{FeO}+2 \mathrm{TiO}_{2}$ mole fractions.

It was observed that the viscosity decreases as the $\mathrm{CaO}$ content increases (see Van Dyk et al., 2009b).

Yong et al., (2010) combined the suggestions made by Wang et al., (2007) and Seggiani (1998) and provided an energy balance for the steady state case where a cubic temperature profile was assumed across the molten slag layer.

Another area of similar behavior or response between molten steel and slag is the viscoelastic response of such materials, where, at high temperatures, the time dependent constitutive relations are needed not only for the stress-stress relationship, but also for the heat flux vector. In an important paper Kozlowski et al., (1992) suggested four types of elastic-viscoplastic constitutive relations of the type:

$$
\begin{aligned}
& \dot{\varepsilon}_{\mathrm{p}}=\dot{\varepsilon}_{\mathrm{p}}(\sigma, \theta) \\
& \dot{\varepsilon}_{\mathrm{p}}=\dot{\varepsilon}_{\mathrm{p}}(\sigma, \theta, \mathrm{t}) \\
& \dot{\varepsilon}_{\mathrm{p}}=\dot{\varepsilon}_{\mathrm{p}}\left(\sigma, \theta, \varepsilon_{\mathrm{p}}\right) \\
& \dot{\varepsilon}_{\mathrm{p}}=\dot{\varepsilon}_{\mathrm{p}}\left(\sigma, \theta, \varepsilon_{\mathrm{p}}, \mathrm{t}\right)
\end{aligned}
$$

where they suggested using the standard Hooke's law for the stress-strain relationship, i.e.,

$$
\dot{\sigma}=\mathrm{E} \dot{\varepsilon}_{\mathrm{e}}
$$

where

$$
\dot{\varepsilon}=\dot{\varepsilon}_{\mathrm{e}}+\dot{\varepsilon}_{\mathrm{p}}+\dot{\varepsilon}_{\theta}
$$

where $\dot{\sigma}$ is the stress rate, $\dot{\varepsilon}$ is the total strain rate, $\dot{\varepsilon}_{\mathrm{e}}$ is the elastic strain rate, $\dot{\varepsilon}_{\mathrm{p}}$ is the inelastic (plastic) strain rate, $\dot{\varepsilon}_{\theta}$ is the thermal strain rate, and $\theta$ is the temperature in Kelvin. A significant contribution of this work was the recognition of the difficulty of measuring and the importance that the Young's modulus E plays in this kind of problem. They used the experimental results of Mizukami et al. (1977), where

$$
\mathrm{E}[\mathrm{GPa}]=968-2.33(\theta-273)+1.90 \times 10^{-3}(\theta-273)^{2}-5.18 \times 10^{-7}(\theta-273)^{3}
$$


This equation is valid for the range of $900{ }^{\circ} \mathrm{C}$ and the liquidus. For the four mentioned models, Kozlowski et al., (1992) suggested various constitutive relations for $\dot{\varepsilon}_{\mathrm{p}}$ as functions of stress, temperature, carbon content, activation energy, and various adjustable parameters such as temperature dependent stress exponent, etc. (see also Thomas 1995, 2002 for a review of this subject).

In the continuous casting of steel, when mold powder is added to the free surface of the liquid steel, it begins to melt and flow. The re-solidified mold powder, also called slag forms a layer adjacent to the walls; there is an increase in its viscosity and it begins to act as a solid-like material (see Meng and Thomas 2003a,b). Once the slag cools, it creates a glassy layer. Heat conduction across the slag layer plays a major role in the operation; it is a function of the thickness of the slag and depends on the conductivity of the various layers and particles embedded in the slag. In the model that they developed, Meng and Thomas (2003a) suggested that the viscosity of molten slag depends on the temperature in the following way:

$$
\mu(\theta)=\mu_{0}\left(\frac{\theta_{0}-\theta_{\text {fsol }}}{\theta-\theta_{\text {fsol }}}\right)^{n}
$$

where $\theta_{\text {fsol }}$ and $n$ are empirical constants chosen to fit the measured data, $\mu_{0}$ is a reference viscosity measured at the reference temperature, and $\theta_{0}$ is usually chosen to be $1300{ }^{\circ} \mathrm{C}$. Meng and Thomas (2003b) suggested that shear stress in the liquid slag can be represented by

$$
\tau_{\mathrm{xz}}=\mu \frac{\partial \mathrm{v}_{\mathrm{z}}}{\partial \mathrm{x}}
$$

where $\mu$ is given by the above equation, while recognizing that in the slag layer the viscosity can be represented by a position-dependent function such that

$$
\tau_{\mathrm{xz}}=\mu_{0} \frac{\mathrm{d}_{1}^{\mathrm{n}}}{\mathrm{x}^{\mathrm{n}}} \frac{\partial \mathrm{v}_{\mathrm{z}}}{\partial \mathrm{x}}
$$

where $d_{1}$ is the liquid film thickness. Meng and Thomas (2006) developed heat transfer and solidification models that consist of a one-dimensional transient heat conduction in the solidifying steel shell and a two-dimensional steady state heat conduction in the water-cold copper mold. To calculate the effective heat transfer coefficient $h_{\text {gap }}$ between the surrounding surface of the steel shell, $\theta_{\mathrm{s}}$, and hot surface of the mold wall, $\theta_{\text {hotc }}$, they suggested an equation of the following type:

$$
\mathrm{q}_{\text {int }}=\mathrm{h}_{\text {gap }}\left(\theta_{\mathrm{s}}-\theta_{\text {hotc }}\right)
$$

where $h_{\text {gap }}$ depends on the thermal resistance of the various (four) layers of materials contained in the gap.

In the continuous casting of steel, it has been observed that the viscosity of the molten slag or flux varies with the composition of the various elements present and the temperature. For example, most commercial fluxes contain (0-13\%) $\mathrm{Al}_{2} \mathrm{O}_{3}$, (22- 
45\%) $\mathrm{CaO}$, and (17-56\%) $\mathrm{SiO}_{2}$, with small amounts of fluorides ( $\mathrm{NaF}, \mathrm{CaF}_{2}$ ), alkalis $\left(\mathrm{Na}_{2} \mathrm{O}, \mathrm{K}_{2} \mathrm{O}\right.$ ) and other basic oxides ( $\mathrm{MgO}, \mathrm{BaO}$ ) (see Zhao et al., (2005). It is well known that the viscosity of liquid flux can be represented by an Arrhenius equation of the following type:

$$
\mu=A \exp \left(\frac{E}{R \theta}\right)
$$

As the powder sinters, its viscosity is increased greatly. Riboud and Larrecq (1979) suggest an alternative equation:

$$
\mu=\mathrm{A} \theta \mathrm{e}^{\mathrm{B} / \theta}
$$

where

$$
\begin{aligned}
& \ln \mathrm{A}=-20.81-35.75 \mathrm{x}_{\mathrm{Al}_{2} \mathrm{O}_{3}}+1.73 \mathrm{x}_{\mathrm{CaO}}+5.82 \mathrm{x}_{\mathrm{CaF}_{2}}+7.02 \mathrm{x}_{\mathrm{Na}_{2} \mathrm{O}} \\
& \mathrm{B}=31140+68833 \mathrm{x}_{\mathrm{Al}_{2} \mathrm{O}_{3}}-23896 \mathrm{x}_{\mathrm{CaO}}-46351 \mathrm{x}_{\mathrm{CaF}_{2}}-39519 \mathrm{x}_{\mathrm{Na}_{2} \mathrm{O}}
\end{aligned}
$$

where $\mu$ is the viscosity measured in Pa.s, $\theta$ is the temperature in degree Kelvin, and $\mathrm{x}$ is the mole fraction of the constituent. For a typical flux (see Zhao et al., 2005), B is $\sim 24000$. To study for a range of fluxes, Zhao et al., (2005) suggested an equation of the type

$$
\mu=\mu_{0} \frac{\theta}{\theta_{0}} \mathrm{e}^{\mathrm{B}^{\left(\frac{1}{\theta}-\frac{1}{\theta_{0}}\right)}}
$$

where $\theta_{0}$ is a reference temperature $(1773 \mathrm{~K}), \mu_{0}$ is a reference viscosity $(0.05 \mathrm{~Pa} \cdot \mathrm{s})$ and $\mathrm{B}$ is a parameter representing the temperature dependency of the flux viscosity. Zhao et al., (2005) also considered the effects of another commonly used equation, namely

$$
\mu(\theta)=\mu_{0}\left(\frac{\theta_{0}-\theta_{s}}{\theta-\theta_{s}}\right)^{n}
$$

where $\mu_{0}$ is the reference viscosity at the reference temperature $\theta_{0}$ of $1300{ }^{\circ} \mathrm{C}$, and $\theta_{\mathrm{s}}$ is a fitting parameter.

In the next section of this report, we review and discuss the various existing implicit constitutive models for non-linear viscoelastic materials that can be used to model the rheological characteristics of slag. 


\section{CONSTITUTIVE MODELING OF SLAG}

As evidenced in section 3 of this report, the viscosity of slag is the most important parameter in determining the proper operating conditions for a gasifier. However, viscosity is only one of the important rheological parameters of importance and since slag, in general, behaves as a non-linear fluid, we must study the constitutive modeling of slag.

\subsection{Background}

The stress tensor and the heat flux vector are two important constitutive relations needed to study flow and heat transfer in complex fluid-like materials (ignoring the effects of radiation). From an engineering perspective, this oftentimes translates into measuring viscosity and thermal conductivity. As a result, most researchers have attempted to generalize Newton's law of viscosity and Fourier's law of heat conduction to various and more complicated cases by assuming that the shear viscosity and/or thermal conductivity could depend on a host of parameters, such as shear rate, temperature, porosity, etc. This does not fully take into account the non-linear and timedependent nature (e.g., normal stress effects or visco-elastic response) of these complex materials, since these generalizations cannot give rise to implicit constitutive relations (see Rajagopal 2006; Massoudi 2005, 2006a, b). A more rigorous approach is to model the stress tensor and the heat flux vector.

While a constitutive equation is a postulate or a definition from the mathematical standpoint, physical experience remains the first guide, perhaps reinforced by experimental data. Constitutive relations are also required to satisfy some general principles. Wang and Truesdell (1973, p. 135) list six general principles: (1) Determinism, (2) Local action, (3) Equipresence, (4) Universal dissipation, (5) Material frame-indifference, and (6) Material symmetry. First, they should hold equally in all inertial coordinate systems at any given time (often referred to as coordinate invariance requirement). This guards against proposing a relation in which a mere change of coordinate description would imply a different response in the material. Many of the socalled "power law" models used in describing non-Newtonian fluids are not coordinateinvariant. In general, this difficulty can easily be overcome by stating the equations either in tensorial form or by using direct notations that do not employ coordinates at all. The principle of material frame-indifference (sometimes referred to as Objectivity), which requires that the constitutive equations be invariant under changes of frame, is perhaps the most important of all. This principle is a consequence of the classical physics principle that states material properties are independent of the observer's frame of reference. It requires that constitutive relations depend only on frame-indifferent forms (or combinations thereof) of the variables pertaining to the given problem.

The following approaches are valuable to modeling complex materials: (i) using physical and experimental models, (ii) doing numerical simulations, (iii) using statistical mechanics approaches, and (iv) ad-hoc approaches. In general, based on available experimental observations, many slags exhibit characteristics similar to those of nonlinear materials, such as colloidal suspensions, polymers, rubber, granular materials, etc. The main points of departure from linear behavior are- 
(1)The ability to shear-thin or shear-thicken

(2)The ability to creep

(3)The ability to relax stresses

(4)The presence of normal stress differences in simple shear flows

(5)The presence of yield stress

The non-linear time-dependent response of complex fluids constitutes an important area of mathematical modeling of non-Newtonian fluids. For many practical engineering cases, where complex fluids such as paint and slurries are used, shear viscosity can be a function of one or all of the following: time; shear rate; concentration; temperature; pressure; electric field; magnetic field, etc. Thus, in general,

$$
\mu=\mu(\mathrm{t}, \pi, \theta, \phi, \mathrm{p}, \mathbf{E}, \mathbf{B}, \ldots)
$$

where $t$ is the time, $\pi$ is some measure of the shear rate, $\theta$ is temperature, $\phi$ is concentration, $\mathrm{p}$ is pressure, $\mathbf{E}$ is electric field, and $\mathbf{B}$ is the magnetic field. Of course, in certain materials or under certain conditions, the dependence of one or more of these can be dropped.

This section of the report is not intended to be comprehensive of all existing models; rather, the aim is to be representative and discuss a few sample cases.

\subsection{Yield Stress}

The yield condition is often related to the angle of repose, friction, and cohesion among other things ${ }^{5}$. Bingham (1922, p. 215) proposed a constitutive relation for a viscoplastic material in a simple shear flow where the relationship between the shear stress (or stress $\mathbf{T}$ in general), and the rate of shear (or the symmetric part of the velocity gradient D) is given by the following (see Prager 1989, p. 137):

$$
2 \mu D_{i j}=\left\{\begin{array}{l}
0 \text { for } \quad \mathrm{F}<0 \\
\mathrm{FT}_{\mathrm{ij}}^{\prime} \text { for } \mathrm{F} \geq 0
\end{array}\right\}
$$

where $\mathrm{T}_{\mathrm{ij}}^{\prime}$ denotes the stress deviator and $\mathrm{F}$, called the yield function, is given by

$$
\mathrm{F}=1-\frac{\mathrm{K}}{\mathrm{II}_{2}^{\prime 1 / 2}}
$$

where $\mathrm{II}_{2}^{\prime}$ is the second invariant of the stress deviator, and in simple shear flows it is equal to the square of the shearing stress and $\mathrm{K}$ is called yield stress (a constant). For onedimensional flow, these relationships reduce to the ones proposed by Bingham (1922):

\footnotetext{
${ }^{5}$ Mohr-Coulomb is perhaps the most popular yield criterion for granular materials, although it is by no means the only one (see Massoudi and Mehrabadi 2001).
} 


$$
\mathrm{F}=1-\frac{\mathrm{K}}{\left|\mathrm{T}_{12}\right|}
$$

and

$$
2 \mu D_{12}=\left\{\begin{array}{ll}
0 & \text { for } F<0 \\
F_{12} & \text { for } \mathrm{F} \geq 0
\end{array}\right\}
$$

The constitutive relation (2a.1) is known as the Bingham model (see also Ziegler 1983, p. 170, or Zhu et al 2005).

Casson (1959) considered that the suspended particles flocculate into rod-like structures, which are broken into primary particles as the shear rate increases. He then developed the following widely used empirical model for the tension in rods under flow.

$$
\tau^{1 / 2}=\tau_{\mathrm{O}}^{1 / 2}+\mu_{\infty}^{1 / 2} \gamma^{1 / 2}
$$

In this equation $\tau_{\mathrm{o}}$ is the yield stress, $\mu_{\infty}$ is the suspension viscosity at infinite shear rate and $\gamma$ is the shear rate. One of the inherent limitations of such empirical models is that they are, in general, one-dimensional, and it is not that easy or straightforward to generalize and obtain the appropriate three-dimensional forms, which are often necessary to solve general three-dimensional problems. Nevertheless, this equation has been successful for a range of parameters and a class of fluids.

Tardos (1997) showed that Schaffer's (1987) model, which can be put in the form

$$
T_{i j}=p\left(\delta_{i j}+\sqrt{2} \sin \varphi \frac{D_{i j}}{\left|D_{i j}\right|}\right)
$$

where $\varphi$, is the internal angle of friction, is similar to some earlier non-Newtonian fluid models proposed by Oldroyd (see Oldroyd 1984) to describe the Bingham solid (see Lipscomb and Denn 1984):

$$
\mathrm{T}_{\mathrm{ij}}=\mathrm{p} \delta_{\mathrm{ij}}+\left(\mu+\frac{\tau_{0}}{\left|\mathrm{D}_{\mathrm{ij}}\right|}\right) \mathrm{D}_{\mathrm{ij}}
$$

Tardos indicates that this constitutive relation differs from (4.6) "by the solid having, in addition to the constant yield strength $\tau_{0}$ (instead of the stress dependent form $p \sin \varphi$ ), a shear viscosity $\mu$." Cowin (1974b) showed that by including the gradient of the volume fraction as one of the important parameters in proposing a constitutive equation for the stress tensor, a theory could be devised for the flow of granular materials. In this theory, a critical yield condition called the Mohr-Coulomb emerges naturally, as does the transition between the frictional flow regimes, characterized by the absence of deformation, and the viscous flow regime, characterized by deformation.

In a coal-water paste (CWP) atomization system with a high concentration of coal and wide particle size distribution, such as those used in pressurized fluidized-bed combustion (PFBC) facilities, the CWP is often modeled as a Herschel-Bulkely model 
(see Tanner 1985, p. 146) where the effect of yield (using Bingham plastic type model) and shear-rate dependence (using the Power-law model) are combined:

$$
\begin{aligned}
& \mathrm{T}_{\mathrm{ij}}=2 \mu_{0} \mathrm{D}_{\mathrm{ij}} \text { when } \dot{\gamma} \leq \dot{\gamma}_{\mathrm{c}} \\
& \mathrm{T}_{\mathrm{ij}}=2\left\{\frac{\tau_{\gamma}}{\dot{\gamma}}+\mathrm{k}|\dot{\gamma}|^{\mathrm{n}-1}\right\} \mathrm{D}_{\mathrm{ij}} \text { when } \dot{\gamma}>\dot{\gamma}_{\mathrm{c}}
\end{aligned}
$$

where $\dot{\gamma}_{c}$ is a critical shear rate.

\subsection{Effects of Concentration, Shear Rate, Temperature, and Pressure}

\subsubsection{Concentration Effect}

The problem of theoretical determination of the viscosity of a dilute suspension consisting of an incompressible Newtonian fluid and rigid sphere particles was studied by Einstein (1956) who derived the classical formula for the effective viscosity of the suspension:

$$
\mu=\mu_{\mathrm{f}}(1+2.5 \phi)
$$

where $\mu_{\mathrm{f}}$ is the viscosity of the fluid base and $\phi$ is the particle volume fraction, which was assumed to be very small compared with unity. Later, Taylor (1932) showed that if the spheres are small drops of another fluid, then the viscosity of the suspension is given by

$$
\mu=\mu_{\mathrm{f}}\left[1+2.5 \phi\left(\frac{\mu_{\mathrm{d}}+\frac{2 \mu_{\mathrm{f}}}{5}}{\mu_{\mathrm{d}}+\mu_{\mathrm{f}}}\right)\right]
$$

where $\mu_{\mathrm{d}}$ is the viscosity of the liquid drops and $\mu_{\mathrm{f}}$ is the viscosity of the base fluid. Batchelor and Green (1972) considered the effect due to the Brownian motion of particles for an isotropic suspension of rigid sphere and spherical particles. They derived a formula for the effective viscosity including the terms of order $\phi^{2}$ and showed that

$$
\mu=\mu_{\mathrm{f}}\left(1+2.5 \phi+7.6 \phi^{2}\right)
$$

where $\phi<1$. The non-linear dependence of the viscosity on the particle volume fraction observed here indicates significant interparticle interaction. As the particle volume fraction increases, the distance between particles decreases. As a result, a significant amount of the liquid is trapped between particles and becomes less mobile. This, in turn, causes the flow around a particle to be influenced by the flow induced by other particles. To account for such interactions, Brinkman (1952), Roscoe (1952), Krieger-Dougherty (1959), Nielsen (1970), and Mooney (1951) used the differential effective medium approach for hard sphere suspension to extend Einstein's formula to a moderate particle volume fraction of about 0.04 . Some of these models are as follows: 
Brinkman (1952)

$$
\mu=\frac{\mu_{\mathrm{f}}}{(1-\phi)^{2.5}}
$$

Roscoe (1952)

$$
\mu=\mu_{\mathrm{f}}(1-\phi)^{-2.5}
$$

Krieger-Dougherty (1959)

$$
\mu=\mu_{\mathrm{f}}\left(1-\frac{\phi}{\phi_{\mathrm{m}}}\right)^{-2.5 \phi_{\mathrm{m}}}
$$

Nielsen (1970)

$$
\mu=\mu_{\mathrm{f}}(1+1.5 \phi) \mathrm{e}^{\phi /\left(1-\phi_{\mathrm{m}}\right)}
$$

Mooney (1951)

$$
\mu=\mu_{\mathrm{f}} \exp \left[\frac{2.5 \phi}{1-\mathrm{K} \phi}\right]
$$

where $\mathrm{K}$ is the crowding factor. Based on Mooney's equation, Choi et al (2000) and Kwon et al., (1998) developed an expression for non-spherical particles:

$$
\ln \left(\frac{\mu}{\mu_{\mathrm{f}}}\right)=\frac{\mu_{\infty} \phi}{1-\phi / \phi_{\mathrm{m}}}
$$

where $\phi_{\mathrm{m}}$ is the maximum packing volume fraction.

\subsubsection{Normal Stress Effects and Shear-Rate Dependent Viscosity}

Perhaps the simplest model to capture the normal stress effects (which could lead to phenomena such as 'die-swell' and 'rod-climbing'--manifestations of the stresses that develop orthogonal to planes of shear) is the second grade fluid, or the Rivlin-Ericksen fluid of grade two (Rivlin and Ericksen 1955, Truesdell and Noll 1992). This model has been used and studied extensively (Dunn and Fosdick 1974) and is a special case of differential-type fluids. For a second grade fluid, the Cauchy stress tensor is given by

$$
\mathbf{T}=-\mathrm{p} \mathbf{1}+\mu \mathbf{A}_{1}+\alpha_{1} \mathbf{A}_{2}+\alpha_{2} \mathbf{A}_{1}{ }^{2}
$$

where $\mathrm{p}$ is the indeterminate part of the stress due to the constraint of incompressibility, $\mu$ is the coefficient of viscosity, $\alpha_{1}$ and $\alpha_{2}$ are material moduli, which are commonly 
referred to as the normal stress coefficients. The kinematical tensors $\mathbf{A}_{1}$ and $\mathbf{A}_{2}$ are defined through

$$
\begin{gathered}
\mathbf{A}_{1}=\mathbf{L}+\mathbf{L}^{\mathrm{T}} \\
\mathbf{A}_{2}=\frac{\mathrm{d} \mathbf{A}_{1}}{\mathrm{dt}}+\mathbf{A}_{1} \mathbf{L}+(\mathbf{L})^{\mathrm{T}} \mathbf{A}_{1} \\
\mathbf{L}=\operatorname{grad} \mathbf{u}
\end{gathered}
$$

The thermodynamics and stability of second grade fluids have been studied in detail by Dunn and Fosdick (1974). They show that if the fluid is to be thermodynamically consistent in the sense that all motions of the fluid meet the Clausius-Duhem inequality and that the specific Helmholtz free energy of the fluid is a minimum in equilibrium, then

$$
\begin{aligned}
& \mu \geq 0, \\
& \alpha_{1} \geqq 0, \\
& \alpha_{1}+\alpha_{2}=0
\end{aligned} .
$$

It is known that for many non-Newtonian fluids, which are assumed to obey equation (4.19), the experimental values reported for $\alpha_{1}$ and $\alpha_{2}$ do not satisfy the restriction (4.21a,b). In an important paper, Fosdick and Rajagopal (1979) show that irrespective of whether $\alpha_{1}+\alpha_{2}$ is positive, the fluid is unsuitable if $\alpha_{1}$ is negative ${ }^{6}$. Furthermore, second grade fluids (or higher order models) raise the order of differential equations by introducing higher order derivates into the equations. As a result, one needs additional boundary conditions; for a discussion of this issue, see Rajagopal (1995), and Rajagopal and Kaloni (1989). In an effort to obtain a model that does exhibit both normal stress effects and shear-thinning/thickening, Man (1992) modified the constitutive equation for a second grade fluid by allowing the viscosity coefficient to depend upon the rate of deformation. The two proposed models are as follows: (see Massoudi and Vaidya 2008):

where

$$
\begin{aligned}
& \mathbf{T}=-\mathrm{p} \mathbf{1}+\mu \Pi^{\mathrm{m} / 2} \mathbf{A}_{1}+\alpha_{1} \mathbf{A}_{2}+\alpha_{2} \mathbf{A}_{1}^{2} \\
& \mathbf{T}=-\mathrm{p} \mathbf{1}+\Pi^{\mathrm{m} / 2}\left(\mu \mathbf{A}_{1}+\alpha_{1} \mathbf{A}_{2}+\alpha_{2} \mathbf{A}_{\mathbf{1}}^{2}\right)
\end{aligned}
$$

$$
\Pi=\frac{1}{2} \operatorname{tr} \mathbf{A}_{1}^{2}
$$

is the second invariant of the symmetric part of the velocity gradient, and $\mathrm{m}$ is a material parameter. When $\mathrm{m}<0$, the fluid is shear-thinning, and if $\mathrm{m}>0$, the fluid is shearthickening; in equation (4.22a) only the shear viscosity depends on the shear rate, whereas in equation (4.22b) the viscosity and the normal stress coefficients are dependent

\footnotetext{
${ }^{6}$ In particular, they showed that if

$\mu>0, \alpha_{1}<0, \alpha_{1}+\alpha_{2} \neq 0$

which many experiments have reported to be the case "for those fluids which the experimentalists assume to be constitutively determined by (4.21), at least sufficiently well as a second order approximation” (Fosdick and Rajagopal, p. 147), then certain anomalous results follow. Fosdick and Rajagopal (1979) proved a theorem that indicates if $(\dagger)_{2,3}$ hold, then a behavioral property not to be expected for any rheological fluid occurs, namely, "that the larger the viscosity, keeping everything else fixed, the faster that initial data is amplified in motions which take place under strict isolation.”
} 
upon shear rate. Both constitutive equations are capable of predicting shear-thinning as well as shear-thickening.

For many fluids, such as polymers, slurries and suspensions, some generalizations have been made to model shear dependent viscosities. These fluids are known as the Power-Law models or the generalized Newtonian fluid models. These models are deficient in many ways: they cannot predict the normal stress differences or yield stresses; they cannot capture the memory or history effects. At the same time, the powerlaw models have been used for a variety of applications where the shear viscosity is not constant (Macosko 1994, Bird et al. 1977, Slattery 1999). A subclass of models given by equation (4.22) is the generalized power-law model, which can be obtained by setting $\alpha_{1}$ $=\alpha_{2}=0$ :

$$
\mathbf{T}=-\mathrm{p} \mathbf{1}+\mu_{0}\left(\operatorname{tr} \mathbf{A}_{1}^{2}\right)^{\mathrm{m}} \mathbf{A}_{\mathbf{1}}
$$

\subsubsection{Temperature Effect}

Gupta and Massoudi (1993) generalized the model given by equation (4.22a), by allowing the shear viscosity to be a function of temperature:

$$
\mathbf{T}=-\mathrm{p} \mathbf{1}+\mu(\theta) \prod^{\mathrm{m} / 2} \mathbf{A}_{1}+\alpha_{1} \mathbf{A}_{2}+\alpha_{2} \mathbf{A}_{1}^{2}
$$

where $\mu(\theta)$ was assumed to obey the Reynolds viscosity model (see Szeri 1998),

$$
\mu(\theta)=\mu_{0} \mathrm{e}^{-\mathrm{M} \theta}
$$

where $\mathbf{M}=\mathrm{n}\left(\theta_{2}-\theta_{1}\right)$. This model is applicable to many processes where preheating of the fuel is used to enhance heat transfer effects. In addition, for many fluids such as lubricants, polymers, and coal slurries where viscous dissipation is substantial, an appropriate constitutive relation where viscosity is a function of temperature should be used. Viscosity changes due to temperature also have significant effects on the stability of flows such as Benard convection, which is the cellular motion whenever a fluid layer is heated from below.

\subsubsection{Pressure Effects}

The various types of "grade" fluids (or fluids of differential type) would fall in the category of explicit constitutive relations. However, for many fluids (known as the ratedependent models, such as Maxwell or Oldroyd models) the rate of the stress tensor $\mathbf{T}$ is described implicitly as a function of $\mathbf{T}$ and $\mathbf{D}$. Another class of implicit constitutive theories (whereby $\mathbf{T}$ depends not only on $\mathbf{D}$, but also the viscosity) that depend on pressure have been proposed by Rajagopal et al. where

$$
\mathbf{T}=-\mathbf{p} \mathbf{1}+\rho v \mathbf{D}
$$

where $v=v\left(p,|\mathbf{D}|^{2}\right)$. Franta et al (2005) considered a class of incompressible fluids where viscosity depends not only on pressure but also on shear rate. They considered the 
following forms for the kinematic viscosity:

$$
v_{\mathrm{i}}\left(\mathrm{p},|\mathbf{D}|^{2}\right)=\left[\mathrm{A}+\gamma_{\mathrm{i}}(\mathrm{p})+|\mathbf{D}|^{2}\right]^{\frac{(\mathrm{r}-2)}{2}} ; \quad \mathrm{i}=1,2,3
$$

where $A \in(0,1]$ and $r \in(1,2)$ are constants and $\gamma_{i}$ is given by any of the relationships:

$$
\begin{aligned}
& \gamma_{1}(p)=\left(1+\alpha^{2} p^{2}\right)^{-q / 2} \\
& \gamma_{2}(p)=[1+\exp (\alpha p)]^{-q} \\
& \gamma_{3}(p)=\left\{\begin{array}{l}
\exp (-\alpha q p) \text { if } p>0 \\
1
\end{array}\right.
\end{aligned}
$$

where $\alpha$ and $q$ are constants. They also noted that when $r=2$, all the possible correlations for viscosity given by equation (4.28) reduce to the classical Navier-Stokes viscosity, and when $r \neq 2, q=0$, or $\alpha=0$, the viscosity depends on the second invariants of $\mathbf{D}$, and the model becomes a special case of the general Stokesian fluid. In this paper, we use the simplified form of the equation proposed by Hron et al. (2001) who suggested the following:

$$
\mathbf{T}=-\mathrm{p} \mathbf{1}+2 \mu(\mathrm{p})|\mathbf{D}|^{\mathrm{n}-2} \mathbf{D}
$$

where, when $n=2$, this model reduces to $\mathbf{T}=-\mathrm{p} \mathbf{1}+2 \mu(\mathrm{p}) \mathbf{D}$. When $\mathrm{n} \in<-1,2)$, the fluid is a shear thinning, and when $n>2$, a shear-thickening. This equation is perhaps the simplest form of a pressure-dependent viscosity fluid.

In the final section of this report, we present a few general remarks about modeling issues related to slag viscosity and thermal conductivity. We also propose a simple yet general constitutive relation, which we think would be appropriate for slags. 


\section{CONCLUDING REMARKS}

The sintering process is one of the earliest examples of materials similar to slag. During sintering, solid particles adhere and grow together into a more complex solid body. In many cases, this densification process is accelerated by the presence of a liquid phase (see Kingery and Berg 1955, Kingery 1959, Mehrabadi and Xu 1998, Xu and Mehrabadi 1997). The wetting parameter, or the wettability, traces its source to the study of Young (1805) who related the contact angle (a geometric parameter) to three thermodynamics quantities that account for the physical (interaction) properties of the contacting phases (see Barberis and Capurro 2008 and Kantak and Davis 2004 for a discussion of this issue).

The particle-slag interaction presents another challenging problem. Whether a carbon-containing particle of a given size would settle at the boundary on the slag layer or get entrapped inside the slag depends on many factors, such as the angle of contact, slag viscosity, forces acting on the particle, etc., (see Shannon et al., (2008a,b). Another important parameter in understanding and controlling the slag layer is the surface tension of molten slag, which is especially significant in the refining or continuous-casting process of making steel (see Hanano et al., (2007). The slag layer could potentially cause degradation of the refractory liner. Chemical dissolution, erosion, chemical spalling and structural spalling are among the important parameters affecting the mechanism involved in the slag-refractory in a gasifier (see Nakano et al., 2011).

The removal of nonmetallic inclusions using direct absorption methods into the slag layer is an important problem in steelmaking industries. Among the important forces influencing this process are drag, capillary, and fluid added mass. Shannon et al., (2008) suggested using the Brenner drag model, which like many other drag models includes the viscosity of slag. When there is contact between an oxide particle and a molten oxide slag phase, at least two important phenomena occur (see Soll-Morris et al., 2009): (1) how the particle responds and whether it settles into the slag (depending on the interaction forces, especially drag, capillary, added mass, etc.) and (2) whether the particle will dissolve into the slag, depending on the slag and oxide properties, particle concentration, etc.

Interestingly, materials that apparently have nothing in common can be expressed rheologically in a similar manner. For example, many studies indicate that for lava (Griffiths 2000), or coal slurries (Tsai et al. 1988) viscosity is a function of temperature, volume fraction, and size and shape of the particles. In many applications, for example melt fraction (Renner et al. (2000) and basaltic lavas, the apparent viscosity is assumed to follow the Einstein-Roscoe relation (Roscoe 1952, 1953):

$$
\eta(\theta, \phi)=\eta_{0}\left(1-\frac{\phi}{\phi_{\max }}\right)^{-2.5} \mathrm{e}^{\gamma\left(\theta_{0}-\theta\right)}
$$

where $\phi_{\max }$ is the maximum crystal fraction in which flow can occur, $\theta_{0}$ and $\eta_{\mathrm{o}}$ are reference values, and $\gamma$ is a constant.

For a complex suspension where the material exhibits normal stress effects and the shear viscosity depends on volume fraction, temperature, and shear rate, Massoudi and Phuoc (2004) suggest the following simple constitutive relation can be used: 


$$
\mathbf{T}=-\mathrm{p} \mathbf{1}+\mu(\theta, \phi) \Pi^{\mathrm{m} / 2} \mathbf{A}_{1}+\alpha_{1} \mathbf{A}_{2}+\alpha_{2} \mathbf{A}_{1}^{2}
$$

where $\mu(\theta, \phi)$ is given by an equation similar to equation (5.1). This model is a general frame invariant model, suitable for flows of non-linear fluids with the viscosity being a function of temperature, concentration, and shear rate, and the material exhibiting both normal stress differences. Obviously the methodology that we have presented here is not very rigorous. For example, the thermodynamics and stability treatments for these constitutive relations, except for the standard second grade fluid, are not available and studies done on these models have been limited to a class of boundary value problems. 


\section{REFERENCES}

Anand, L. Constitutive Equations for the Rate Dependent Deformation of Metals at Elevated Temperatures. ASME J. Eng. Mater. Technol. 104 (1982): 12-17.

Atkin, R.J.; Craine, R.E. Continuum Theories of Mixtures: Basic Theory and Historical Development. Q. J.. Mech. and Appl. Math. 29 (1976): 209-244.

Atkin, R.J.; Craine, R.E. Continuum Theories of Mixtures: Applications. J. Inst. Math. Applications 17 (1976): 153-207.

Backreedy, R.I.; Fletcher, L.M.; Jones, J.M.; Ma, L.; Pourkashanian, M.; Williams, A. Co-firing Pulverized Coal and Biomass: A Modeling Approach. Proc. Combustion Institute 30 (2005): 2995-2964.

Bale, C. W.; Pelton, A.D.; Thompson, W.T. Facility for the Analysis of Chemical Thermodynamics (FACT). Ecole Polytechnique: Montreal, 1996.

Barberis, F.; Capurro, M. Wetting in the Nanoscale: A Continuum Mechanics Approach. J. Colloid Interface Sci. 326 (2008): 201-210.

Batchelor, G.K. Transport Properties of Two-Phase Materials with Random Structure. Annual Rev. Fluid Mech. 6 (1974): 225-255.

Batchelor, G.K.; Green, J.T. Determination of Bulk Stress in a Suspension of Spherical-Particle to Order C-2. J. Fluid. Mech. 56 (1972): 401-427.

Beevers, C. E.; Craine, R.E. On the Determination of Response Functions for a Binary Mixture of Incompressible Newtonian Fluids. Int. J. Engng. Sci. 20 (1982): 737745.

Bills, P.M. Viscosities in Silicate Slag Systems. J. Iron Steel Institute 201 (1963): 133140.

Bingham, E.C. Fluidity and Plasticity. McGraw Hill: New York, 1922.

Bird, R.B.; Armstrong, R.C.; Hassager, J. Dynamics of Polymeric Liquids. John Wiley \& Sons: New York, 1977; Vol. 1.

Bjorkvall, J.; Sichen, D.; Stolyarova, V.; Seetharaman, S. A Model Description of the Thermomechanical Properties of Multicomponent Slags and Its Application to Slag Viscosities. Glass Physics Chemistry 27 (2001): 132-147.

Bockris, J. O’M.; Reddy, A. K. N. Modern Electrochemistry. Plenum Press: NY, 1970; p. 574. 
Bowen, R.M. Theory of Mixtures. Continuum Physics. Eringen, A.C., Ed. Academic Press: New York, 1976; Vol. 3.

Breault, R.W. Gasification Process Old and New: A Basic Review of the Major Technologies. Energies 3 (2010): 216-240.

Bridgwater, A.V. Renewable Fuels and Chemical by Thermal Processing of Biomass. Chem. Engng. J. 91 (2003): 87-102.

Bridgwater, A.V.; Toft, A.J.; Brammer, J.G. A Techno-Economic Comparison of Power Production by Biomass Fast Pyrolysis with Gasification and Combustion. Renewable Sust. Energy Rev. 6 (2002): 181-248.

Brinkman, H.C. The Viscosity of Concentrated Suspension and Solution, J. Chem. Phys. 20 (1952): 571-581.

Broadbent, C. P., M. Franken, D. Gould, and K. C. Mills. Proc. Int. Conf on Molten Slags and Fluxes. Sendai, Iron and Steel Inst., Japan, 1992, 439-443.

Browning, G. J.; Bryant, G.W.; Hurst, H.J.; Lucas, J.A.; Wall, T.F. An Empirical Method for the Prediction of Coal Ash Slag Viscosity. Energy Fuels 17 (2003): 731-737.

Buhre, B.J.P.; Browning, G.J.; Gupta, R.P.; Wall, T.F. Measurement of the Viscosity of Coal-Derived Slag Using Thermomechanical Analysis. Energy \& Fuels 19 (2005): 1078-1083.

Casson, N. A Flow Equation for Pigment-Oil Suspensions of the Printing Ink Type. Rheology of Disperse Systems, Mill, C.C., Ed. Pergamon: New York, 1959.

Chen, C.; Horio, M.; Kojima, T. Use of Numerical Modeling in the Design and ScaleUp of Entrained Flow Coal Gasifiers. Fuel 80 (2001): 153-1523.

Choi, H.T.; Kwon, T.M.; Jhon, M.S. Effects of Shear Rate and Particle Concentration on Rheological Properties of Magnetic Particle Suspension. J. Materials Science 35 (2000): 889-894.

Cowin, S.C. A Theory for the Flow of Granular Material. Powder Tech. 9 (1974): 61-69.

Cowin, S.C. Constitutive Relations That Imply a Generalized Mohr-Coulomb Criterion. Acta Mech. 20 (1974b): 41-46.

Ducret, A.C.; Rankin, W.J. Liquidus Temperatures and Viscosities of FeO- $\mathrm{Fe}_{2} \mathrm{O}_{3}$ $\mathrm{SiO}_{2}-\mathrm{CaO}-\mathrm{MgO}$ Slags at Compositions Relevant to Nickel Matte Smelting. Scandinavian J. Metallurgy 31 (2002): 59-67. 
Dunn, J. E.; Fosdick, R.L. Thermodynamics, Stability, and Boundedness of Fluids of Complexity 2 and Fluids of Second Grade. Arch. Rational Mech. Anal. 56 (1974): 191-252.

Easterly, J.; Burnham, M. Overview of Biomass and Waste Fuel Resources for Power Production. Biomass Energy 10 (1996): 77-92.

Einstein, A. Theory of the Brownian Movement. Dover Publications: New York, 1956.

Ekmann, J. M.; Winslow, J.C.; Smouse, S.M.; Ramezan, M. International Survey of Co-firing Coal with Biomass and Other Wastes. Fuels Process. Tech. 54 (1998): 171-188.

Erickson, T.A.; Allen, S.E.; McCollor, D.P.; Hurely, J.P.; et al. Modeling of Fouling and Slagging in Coal-Fired Utility Boilers. Fuel Processing Tech. 44 (1995): 155-171.

Forsbacka, L.; Holappa, L.; Iida, T.; Kita, Y.; Toda, Y. Experimental Study of Viscosities of Selected CaO-MgO- $\mathrm{Al}_{2} \mathrm{O}_{3}-\mathrm{SiO}_{2}$ Slags and Application of the Iida Model. Scandinavian J. Metallurgy 32 (2003): 273-280.

Fosdick, R. L.; Rajagopal, K.R. Anomalous Features in the Model of "Second Order Fluids”. Arch. Rational Mech. Anal. 70 (1979): 145-152.

Franta, M.; Malek, J.; Rajagopal, K.R. On Steady Flows of Fluids with Pressure-and Shear-Dependent Viscosities. Proc. R. Soc. Lond. A 461 (2005): 651-670.

Fu, Y.; Cai, L.; Wu, Y. Freeze-Thaw Cycle Test and Damage Mechanics Models of Alkali-Activated Slag Concrete. Construction Building Materials 25 (2011): 3144-3148.

Groen, J. C.; Brooker, D.D.; Welch, P.J.; Oh, M.S. Gasification Slag Rheology and Crystallization in Titanium-Rich, Iron-Calcium-Aluminosilicate Glass. Fuel Process. Tech. 56 (1998): 103-127.

Griffiths, R.W. The Dynamics of Lava Flows. Annual Review of Fluid Mechanics 32 (2000): 477-518.

Gupta, G.; Massoudi, M. Flow of a Generalized Second Grade Fluid Between Heated Plates. Acta Mech. 99 (1993): 21-33.

Hanao, M.; Tanaka, T.; Kawamoto, M.; Takatani, K. Evaluation of Surface Tension of Molten Slag in Multi-Component Systems. ISIJ International 47 (2007): 935-939.

Hoy, H. R.; Roberts, A.G.; Wilkins, D.M. Behaviour of Mineral Matter in Slagging Gasification Processes. J. Instn Gas Engrs 5 (1965): 444-469. 
Hron J.; Malek, J.; Rajagopal, K. R. Simple Flows of Fluids with Pressure-Dependent Viscosities. Proc. R. Soc. Lond. A 457 (2001): 1603-1622.

Hurst, H.J.; Novak, F.; Patterson, J. H. Viscosity Measurements and Empirical Predictions for Some Model Gasifier Slags. Fuel 78 (1999): 439-444.

Hurst, H.J.; Patterson, J.H.; Quintanar, A. Viscosity Measurements and Empirical Predictions for Some Model Gasifier Slags-II. Fuel 79 (2000): 1797-1799.

Iida, T.; Sakai, H.; Kita, Y.; Shigeno, K. An Equation for Accurate Prediction of the Viscosities of Blast Furnace Type Slags from Chemical Composition. ISIJ International 40 (2000): S110-S114.

Inaba, S.; Kimura, Y. Viscosity Measurement of Slag Formed in the Carbon-Bearing Iron Oxide During Rapid Heating. ISIJ International 44 (2004): 2067-2072.

Jak, E.; Saulov, A.; Kondratiev; Hayes, P.C. Prediction of Phase Equilibria and Viscosity in Complex Coal Ash Slag Systems. Preprint Paper Am. Chem. Soc. Div. Fuel Chem. 49 (2004): 159-162.

Jak, E.; Degetrov, S.; Zhao, B.; Pelton, A.D.; Hayes, P.C. Coupled Experimental and Thermodynamic Modeling Studies for Metallurgical Smelting and Coal Combustion Slag Systems. Metallurgical Materials Trans. B 31B (2000): 621630.

Johnson, E. K. Trans. ASME 106 (1984): 777.

Kalicka Z.; Kawecka-Cebula, E.; Pytel, K. Application of the Iida Model for Estimation of Slag Viscosity for $\mathrm{Al}(2) \mathrm{O}(3)-\mathrm{Cr}(2) \mathrm{O}(3)-\mathrm{CaO}-\mathrm{CaF}(2)$ Systems. Archives of Metallurgy Materials 54 (2009): 179-187.

Kang, T.W.; Gupta, S.; Saha-Chaudhury, N.; Sahajwalla, V. Wetting and Interfacial Reaction Investigations of Coke/Slag Systems and Associated Liquid Permeability of Blast Furnaces. ISIJ International 45 (2005): 1526-1535.

Kantak, A.A.; Davis, R.H. Oblique Collisions and Rebound of Spheres from a Wetted Surface. J. Fluid Mech. 509 (2004): 63-81.

Karamanova, E.; Avdeev, G.; Karamanov, A. Ceramics Form Blast Furnace Slag, Kaolin and Quartz. J. European Ceramic Soc. 31 (2011): 989-998.

Kato, M.; Minowa, S. Viscosity Measurements of Molten Slag-Properties of Slag at Elevated Temperature (Part I). Trans. ISIJ 9 (1969): 31-38.

Kelly, J. E.; Michaleck, K.P.; O’Connor, T.G.; Thomas, B.G.; Dantzig, J.A. Initial 
Development of Thermal and Stress Fields in Continuously Cast Steel Billets. Metallurgical Trans. A 19A (1988): 2589-2602.

Kim H., W. H. Kim, I. Sohn, and D. J. Min. The Effect of MgO on the Viscosity of the $\mathrm{CaO}-\mathrm{SiO}(2)-20$ wt\% Al(2)O(3)-MgO Slag System. Steel Research International, 81 (2010), 261-264.

Kingery, W.D. Densification During Sintering in the Presence of a Liquid Phase. I. Theory. J. Appl. Phys. 30 (1959): 301-306.

Kingery, W.D.; Berg, M. Study of the Initial Stages of Sintering Solids by Viscous Flow, Evaporation-Condensation, and Self-Diffusion. J. Appl. Phys. 26 (1955): 1205-1212.

Kondratiev, A.; Jak, E. Predicting Coal Ash Slag Flow Characteristics (Viscosity Model for the $\mathrm{Al}_{2} \mathrm{O}_{3}-\mathrm{CaO}-{ }^{\prime} \mathrm{FeO}-\mathrm{SiO}_{2}$ System). Fuel 80 (2001): 1989-2000.

Kondratiev, A.; Jak, E. Review of Experimental Data and Modeling of the Viscosities of Fully Liquid Slags in the $\mathrm{Al}_{2} \mathrm{O}_{3}-\mathrm{CaO}-{ }^{-} \mathrm{FeO}$ '- $\mathrm{SiO}_{2}$ System. Metallurgical Materials Trans. B. 32B (2001): 1015-1025.

Kong, L. X.; Bai, J.; Li, W.; Bai, Z.Q.; Guo, Z.X. Effect of Lime Addition on Slag Fluidity of Coal Ash. J. Fuel Chem. Technol. 39 (2011): 407-411.

Koric, S.; Thomas, B.G. Thermo-mechanical Models of Steel Solidification Based on Two Elastic Visco-plastic Constitutive Laws. J. Materials Processing. Tech. 197 (2008): 408-418.

Kozlowski, P.F.; Thomas, B.G.; Azzi, J.A.; Wang, H. Simple Constitutive Equations for Steel at High Temperature. Metallurgical Trans. A 23A (1992): 903-918.

Krieger, I.M.; Dougherty, T.J. A Mechanism for Non-Newtonian Flow in Suspension of Rigid Spheres. Trans. Society Rheology 3 (1959): 137-152.

Kwon, T.M.; Jhon, M.S.; Choi, H.J. Viscosity of Magnetic Particle Suspension. J. Molecular Liquids 75 (1998): 115-126.

Lachemi, M.; Hossain, K.M.A.; Lambros, V.; Bouzoubaa, N. Development of CostEffective Self-Consolidating Concrete Incorporating Fly Ash, Slag Cement, or Viscosity-Modifying Admixtures. ACI Materials J. 100 (2003): 419-425.

Lawn, C.J. (editor). Principles of Combustion Engineering for Boilers. Academic Press: London, 1987.

Lee, F.C.C.; Fletcher, C.A.; Shin, S.H. Prog. Energy Combust. Sci. 25 (1999): 117-132. 
Lipscomb, G.G.; Denn, M.M. Flow of Bingham Fluids in Complex Geometries. $J$. Non-Newtonian Fluid Mech. 14 (1984): 337-346.

Liu, I.S. Continuum Mechanics. Springer-Verlag. Berlin, 2002.

Ma, Z.; Iman, F.; Liu, P.; Sears, R.; Kong, L.; Rokanuzzaman, A.S.; McCollar, D.P.; Benson, S.A. A Comprehensive Slagging and Fouling Prediction Tool for CoalFired Boilers and Its Validation/Application. Fuel Processing Tech. 88 (2007): 1035-1043.

Macosko, C.W. Rheology: Principles, Measurements and Applications. Wiley-VCH: New York, 1994.

Man, C.S. Nonsteady Channel Flow of Ice as a Modified Second-Order Fluid with Power-Law Viscosity. Arch. Rat. Mech. Anal. 119 (1992): 35-57.

Massoudi, M. On the Importance of Material Frame-Indifference and Lift Forces in Multiphase Flows. Chemical Engineering Science 57 (2002): 3687-3701.

Massoudi, M. Constitutive Relations for the Interaction Force in Multi-Component Particulate Flows. Intl. J. Non-linear Mech. 38 (2003): 313-336.

Massoudi, M. On the Heat Flux Vector in Mixtures. Int. Comm. Heat and Mass Transfer 32 (2005): 1128-1134.

Massoudi, M. On the Heat Flux Vector for Flowing Granular Materials, Part I: Effective Thermal Conductivity and Background. Math. Methods Applied Sci. 29 (2006): 1585-1598.

Massoudi, M. On the Heat Flux Vector for Flowing Granular Materials, Part II: Derivation and Special Cases. Math. Methods Applied Sci. 29 (2006): 1599-1613.

Massoudi, M. A Mixture Theory Formulation for Hydraulic or Pneumatic Transport of Solid Particles. Int. J. Engng Sci. 48 (2010): 1440-1461.

Massoudi, M.; Mehrabadi, M.M. A Continuum Model for Granular Materials: Considering Dilatancy, and the Mohr-Coulomb Criterion. Acta Mech. 152 (2001): 121-138.

Massoudi, M.; Phuoc, T.X. Flow of a Generalized Second Grade Non-Newtonian Fluid with Variable Viscosity. Continuum Mech. Thermodyn. 16 (2004): 529-538.

Massoudi, M.; Phuoc, T.X. Flow of a Non-Linear (Density-Gradient-Dependent) Viscous Fluid with Heat Generation, Viscous Dissipation and Radiation. Math. Methods Applied Sci. 31 (2008): 1685-1703. 
Massoudi, M.; Vaidya, A. On Some Generalizations of the Second Grade Fluid Model. Nonlinear Analysis, Part II, Real World Applications, 9 (2008): 1169-1183.

Mazumdar, S.; Ray, S.K. Solidification Control in Continuous Casting of Steel. Sadhana 26 (2001): 179-198.

Mehrabadi, M.M.; Xu, K. Mechanics of Powders in the Initial Rearrangement Stage of Liquid-Phase Sintering. Mech. Materials 28 (1998): 237-245.

Mehta, A.S.; Sahajwalla, V. Coal-Char/Slag Interactions During Pulverized Coal Injection in a Blast Furnace: Reaction Kinetics and Wetting Investigations. ISIJ International 43 (2003): 1512-1518.

Meng, Y.; Thomas, B.G. Heat-Transfer and Solidification Model of Continuous Slab Casting: CON1D. Metallurgical Materials Trans. B 34B (2003): 685-705.

Meng, Y.; Thomas, B.G. Modeling Transient Slag-Layer Phenomena in the Shell/Mold Gap in Continuous Casting of Steel. Metallurgical Materials Trans. B 34B (2003): 707-725.

Meng, Y.; Thomas, B.G. Simulation of Microstructure and Behavior of Interfacial Mold Slag Layers in Continuous Casting of Steel. ISIJ International 46 (2006): 660-669.

Mills, K.C.; Sridhar, S. Viscosities of Ironmaking and Steelmaking. Ironmaking and Steelmaking 26 (1999): 262-268.

Mizukami, H.; Murakami, K.; Miyashita, Y. Tetsu-to-Hagane 63 (1977): S-652.

Montagnaro, F.; Salatino, P. Analysis of Char-Slag Interaction and Near-Wall Particle Segregation in Entrained-Flow Gasification of Coal. Combustion and Flame 157 (2010): 874-883.

Mooney, M.J. The Viscosity of a Concentrated Suspension of Spherical Particles. J. Colloid Science 6 (1951): 162-170.

Mudersbach, D.; Drissen, P.M.; Kuhn, M.; Geiseler, J. Viscosity of Slags. Steel Research 72 (2001): 86-90.

Müller, I. On the Entropy Inequality. Arch. Rat. Mech. and Anal. 26 (1967): 118-141.

Nakamoto, M.; Lee, J.; Tanaka, T. A Model for Estimation of Viscosity of Molten Silicate Slag. ISIJ International 45 (2005): 651-656.

Nakano, J.; Sridhar, S.; Bennett, J.; Kwong, K.S.; Moss, T. Interactions of Refractory 
Materials with Molten Gasifier Slags. Int. J. Hydrogen Energy 36 (2011): 45954604.

Ni, J.; Yu, G.; Guo, Q.; Dai, Z.; Wang, F. Modeling and Comparison of Different Syngas Cooling Types for Entrained-Flow Gasifier. Chem. Eng. Sci. 66 (2011): 448-459.

Nicholls, P.; Reid, W.T. Viscosity of Coal Ash Slags. Trans ASME (1940): 141-153.

Nielsen, L.E. Generalized Equation for the Elastic Moduli of Composite Materials. $J$. Applied Physics 41 (1970): 4626-4627.

Nowok, J.W. Viscosity and Phase Transformation in Coal Ash Slags Near and Below the Temperature of Critical Viscosity. Energy \& Fuels 8 (1994): 1324-1336.

Nowok, J.W. Viscosity and Structural State of Iron in Coal Ash Slags Under Gasification Conditions. Energy \& Fuels 9 (1995): 534-539.

Oldroyd, J.G. An Approach to Non-Newtonian Fluid Mechanics. J. Non-Newtonian Fluid Mech. 14 (1984): 9-46.

Pandey J.C.; Raj, M.; Lenka, S.N.; Suresh, P.; Balasubramaniam, K. Measurement of Viscosity and Melting Characteristics of Mould Powder Slags by Ultrasonics. Ironmaking \& Steelmaking 38 (2011):74-79.

Papastergios, G.; Fernandez-Turiel, J.L.; Georgkopoulos, A.; Gimeno, D. Slag and Ash Chemistry After High-Calcium Lignite Combustion in a Pulverized CoalFired Power Plant. Global NEST J. 9 (2007): 77-82.

Park, S.; Oh, M.S. Slagging of Petroleum Coke Ash Using Korean Anthracites. J. Industrial Eng. Chem. 14 (2008): 350-356.

Patterson, J. H.; Hurst, H.J. Ash and Slag Qualities of Australian Bituminous Coals for Use in Slagging Gasifiers. Fuel 79 (2000): 1671-1678.

Petrick, M.; Shumyatsky, B.Ya. . Open-Cycle Magnetohydrodynamic Electrical Power Generation. A Joint USA/USSR Publication. Argonne National Laboratory. Argonne, IL., 1978.

Pian, C.C.P.; Yoshikawa, K. Development of a High-Temperature Air-Blown Gasification System: Review Paper. Bioresource Tech. 79 (2001): 231-241.

Prager, W. Introduction to Mechanics of Continua. Dover Publications: Mineola, NY, 2004 (1989). 
Rajagopal, K.R. On Boundary Conditions for Fluids of Differential Type. Navier-Stokes Equations and Related Nonlinear Problems. Sequeira, A., Ed. Plenum Press: New York, 1995, 273-278.

Rajagopal, K.R. On Implicit Constitutive Theories for Fluids. J. Fluid Mech. 550 (2006): 243-249.

Rajagopal, K.R.; Kaloni, P.N. Some Remarks on Boundary Conditions for Flows of Fluids of the Differential Type. Continuum Mechanics and its Applications. Hemisphere Press, Washington DC,1989, 935-942.

Rajagopal, K.R.; Tao, L. Mechanics of Mixtures. World Scientific Publishing: New Jersey, 1995.

Reddy, R.G.; Hebbar, K. Viscosity of FeO-SiO 2 . Minerals \& Metallurgical Processing 18 (2001): 195-199.

Reddy, R.G.; Hebbar, K. TMS EPD Congress, 1991, p. 523-540.

Reid, W.T.; Cohen, P. Trans. ASME 66 (1944): 685.

Reiner, M. Rheology. Handbuch Der Physik. Flugge, S., Ed. Springer-Verlag: Berlin, 1958, Vol. VI.

Renner, J.; Evans, B.; Hirth, G. On the Rheologically Critical Melt Fraction. Earth Planet. Sci. Lett. 181 (2000): 585-594.

Rezaei, H.R.; Gupta, R.P.; Bryant, G.W.; et al. Thermal Conductivity of Coal Ash and Slags and Models Used. Fuel 79 (2000): 1697-1710.

Riboud, P.V.; Lareecq, M. In Steelmaking Proceedings ISS-AIME 62 (1979): 78-92.

Rivlin, R.S.; Ericksen, J.L. Stress Deformation Relations for Isotropic Materials, J. Rat. Mech. Anal. 4 (1955): 323-425.

Roscoe, R. The Viscosity of Suspensions of Rigid Spheres. Br. J. Appl. Phys. 3 (1952): 267-269.

Roscoe, R. Suspensions. Flow Properties of Disperse Systems. Hermans, J.J., Ed. North Holland, New York: 1953, 1-38.

Saito, N.; Hori, N.; Nakashima, K.; Mori, K. Viscosity of Blast Furnace Type Slags. Metallurgical and Materials Trans. B 34B (2003): 509-516.

Schaeffer, D.G. Instability in the Evolution Equations Describing Incompressible Granular Flow. J. Diff. Eq. 66 (1987): 19-50. 
Seetharaman S.; Mukai, K.; Sichen, D. Viscosities of Slags--An Overview. Steel Research International 76 (2005): 267-278.

Seggiani, M. Modeling and Simulation of Time Varying Slag Flow in a Prenflo Entrained-Flow Gasifier. Fuel 77 (1998): 1611-1621.

Seok, S. H.; Jung, S.M.; Lee, Y.S.; Min, D.J. Viscosity of Highly Basic Slags. ISIJ International 47 (2007): 1090-1096.

Shahbazian, F. Experimental Studies of the Viscosities in the $\mathrm{CaO}-\mathrm{FeO}-\mathrm{SiO}_{2}-\mathrm{CaF}_{2}$ Slags. Scandinavian J. Metallurgy 30 (2001): 302-308.

Shannon, G.N.; Rozelle, P.L.; Pisupati, S.V.; Sridhar, S. Conditions for Entrainment into a $\mathrm{FeO}_{\mathrm{x}}$ Containing Slag for a Carbon-Containing a Particle in an Entrained Coal Gasifier. Fuel Processing Tech. 89 (2008): 1379-1385.

Shannon, G.; White, L.; Sridhar, S. Modeling Inclusion Approach to the Steel/Slag Interface. Materials Sci. Engng., A 495 (2008): 310-315.

Shu, Q. A Viscosity Estimation Model for Molten Slags in $\mathrm{Al}(2) \mathrm{O}(3)-\mathrm{CaO}-\mathrm{MgO}-\mathrm{SiO}(2)$ System. Steel Research International 80 (2009): 107-113.

Slattery, J.C. Advanced Transport Phenomena. Cambridge University Press, 1999.

Soll-Morris, H.; Sawyer, C.; Zhang, Z.T.; Shannon, G.N.; Nakano, J.; Sridhar, S. The Interaction of Spherical $\mathrm{Al}_{2} \mathrm{O}_{3}$ Particles with Molten $\mathrm{Al}_{2} \mathrm{O}_{3}-\mathrm{CaO}-\mathrm{FeO}_{\mathrm{x}}-\mathrm{SiO}_{2}$ Slags. Fuel 88 (2009): 670-682.

Sondreal, E.A.; Benson, S.A.; Hurley, J.P.; Mann, M.D.; Pavlish, J.H.; Swanson, M.L.; Weber, G.F.; Zygarlicke, C.J.. Review of Advances in Combustion Technology and Biomass Cofiring. Fuel Processing Tech. 71 (2001): 7-38.

Song, W.; Tang, L.; Zhu, X.; Wu, Y.; et al. Flow Properties and Rheology of Slag from Coal Gasification. Fuel 89 (2010): 1709-1715.

Sridhar, S. Estimation Models for Molten Slag and Alloy Viscosities. JOM, November (2002), 46-50.

Stanmore, B.R.; Budd, S. Measuring the Viscous Flow of Molten Coal Ash. Fuel 75 (1996): 1476-1479.

Straughan, B. The Energy Method, Stability and Nonlinear Convection. Springer Verlag: New York, 2004, $2^{\text {nd }}$ edition.

Straughan. B. Stability and Wave Motion in Porous Media. Springer-Verlag: New York, 
2008.

Szeri, A.Z. Fluid Film Lubrication. Cambridge University Press: Cambridge, MA, 1998.

Tanner, R.I. Engineering Rheology. Revised second edition. Oxford University Press: Oxford, 1988.

Tardos, G.I. A Fluid Mechanistic Approach to Slow, Frictional Flow of Powders. Powder Tech. 92 (1997): 61-74.

Taylor, G.I. The Viscosity of a Fluid Containing Small Drops of Another Fluid, Proc. Roy. Soc. London A138 (1932): 41-48.

Thomas, B.G.; Samarasekera, I.V.; Brimacombe, K.J. Mathematical Model of the Thermal Processing of Steel Ingots: Part I. Heat Flow Model. Metallurgical Trans B 18B (1987): 119-130.

Thomas, B.G.; Samarasekera, I.V.; Brimacombe, K.J. Mathematical Model of the Thermal Processing of Steel Ingots: Part II. Stress Model. Metallurgical Trans. B 18B (1987): 131-147.

Thomas, B.G.; Mika, L.J.; Najjar, F.M. Simulation of Fluid Flow Inside a Continuous Slab-Casting Machine. Metallurgical Trans. B 21B (1990): 387-400.

Thomas, B.G. Issues in Thermal-Mechanical Modeling of Casting Processes. ISIJ International 35 (1995): 737-743.

Thomas, B.G. Modeling of the Continuous Casting of Steel--Past, Present, and Future. Metallurgical Materials Trans. B 33B (2002): 795-812.

Thomas, B.G.; Zhang, L. Mathematical Modeling of Fluid Flow in Continuous Casting: Review. ISIJ International 41 (2001): 1181-1193.

Tonmukayakul, N.; Nguyen, Q.D. A New Rheometer for Direct Measurement of the Flow Properties of Coal Ash at High Temperatures. Fuel 81 (2002): 397-404.

Truesdell, C. Rational Thermodynamics. Springer-Verlag, New York, 2nd edition, 1984.

Truesdell, C.; Noll, W. The Non-Linear Field Theories of Mechanics. SpringerVerlag: New York, 1992.

Truesdell, C.; Rajagopal, K.R. An Introduction to the Mechanics of Fluids. Birkhauser: New York, 2000.

Tsai, C. Y.; Novack, M.; Roffe, G. Rheological and Heat Transfer Characteristics of Flowing Coal-Water Mixtures, DOE Report, DOE/MC/23255-2763, December 
1988.

Urbain, G. Viscosities of Estimation of Slags. Steel Research 58 (1987): 111-116.

Urbain, G.; Cambier, F.; Deletter, M.; Anseau, M.R. Trans J. British Ceram. Soc. 80 (1981): 139-141.

Van Dyk, J.C.; Waanders, F.B.; Benson, S.A.; Laumb, M.L.; Hack, K. Viscosity Predictions of the Slag Composition of Gasified Coal, Utilizing FactSage Equilibrium Modeling. Fuel 88 (2009): 67-74.

Van Dyk, J.C.; Benson, S.A.; Laumb, M.L.; Waanders, F.B. Coal and Coal Ash Characteristics to Understand Mineral Transformations and Slag Formation. Fuel 88 (2009): 1057-1063.

Vargas, S.; Frandsen, F.J.; Dam-Johansen, K. Rheological Properties of HighTemperature Melt of Coal Ashes and Other Silicates. Prog. Energy Combust. Sci. 27 (2001): 237-429.

Vorres, K. S.; Greenberg, S.; Poeppel, R. Viscosity of Synthetic Coal Ash Slags. Mineral Matter and Ash in Coal. ACS, Washington, DC: 1986, 156-169.

Walsh, P.M.; Sarofim, A.F.; Beer, J.M. Energy Fuels 6 (1992): 709-715.

Wang, C.-C; Truesdell, C. Introduction to Rational Elasticity. Noordhoff International Publishing: Leyden, 1973.

Wang, H.; Harb, J.N. Modeling of Ash Deposition in Large-Scale Combustion Facilities Burning Pulverized Coal. Prog. Energy Combust. Sci. 23 (1997): 267-282.

Wang, P.; Massoudi, M. Effect of Coal Properties and Operation Conditions on Flow Behavior of Coal Slag in Entrained Flow Gasifiers: A Brief Review. Report number: DOE/NETL-2011/1508. November 2011.

Wang, X. H.; Zhao, D.Q.; He, L.B.; Jiang, L.Q.; Chen, Y. Modeling of a CoalFired Slagging Combustor: Development of a Slag Submodel. Combustion and Flame 149 (2007): 249-260.

Wang, X.; Tan, H.; Niu, Y.; et al. Experimental Investigation on Biomass Co-firing in a 300 MW Pulverized Coal-Fired Utility Furnace in China. Proc. Combustion Institute 33 (2011): 2725-2733.

Watt, J.D.; Fereday, F. The Flow Properties of Slags Formed from the Ashes of British Coals: Part 1. Viscosity of Homogenous Liquid Slags in Relation to Slag Composition. J. Institute of Fuel 42 (1969): 99-103. 
Weymann, H.D. Kolloid Z. Polymer 181 (1962): 131-137.

Willimas, A.; Pourkashanian, M; Jones, J.M. The Combustion of Coal and Some Other Solid Fuels. Proc. Combustion Institute 28 (2000): 2141-2162.

Wright, S.; Zhang, L.; Sun, S.; Jahanshahi, S. Metall. Mater. Trans. B 31 (2000): 97104.

Xu J. F.; Zhang, J.Y.; Jie, C.; Ruan, F.; Chou, K.C. Experimental Measurements and Modeling of Viscosity in $\mathrm{CaO}-\mathrm{Al}(2) \mathrm{O}(3)-\mathrm{MgO}$ Slag System. Ironmaking \& Steelmaking 38 (2011): 329-337.

Xu, K.; Mehrabadi, M.M. A Micromechanical Model for the Initial Rearrangement Stage of Liquid Phase Sintering. Mechanics of Materials 25 (1997): 137-157.

Yong, S Z.; Ghoneim, A; Gazzino, M. Multiphase Models of Slag Layer Built-up in Solid Fuel Gasification and Combustion. In Proc. $35^{\text {th }}$ Tech. Conf. Clean Coal Fuel Systems, Clearwater, FL, 2010, p. 1208-1218.

Young, T. Phil. Trans. Royal Soc., London 95 (1805): 65.

Zbogar, A.; Frandsen, F.J.; Jensen, P.A.; Glarborg, P. Heat Transfer in Ash Deposits: A Modeling Tool-Box. Prog. Energy Combustion Sci. 31 (2005): 371-421.

Zhao, B.; Vanka, S.P.; Thomas, B.G. Numerical Study of Flow and Heat Transfer in a Molten Flux Layer. Int. J. Heat Fluid Flow 26 (2005): 105-118.

Zhu, H. Coupled Thermal-Mechanical Finite-Element Model with Application to Initial Solidification. Ph.D. Thesis. University of Illinois, 1993.

Zhu, H.; Kim, Y.D.; De Kee, D. Non-Newtonian Fluids with a Yield Stress. J. NonNewtonian Fluid Mech. 129 (2005): 177-181.

Ziegler, H. An Introduction to Thermomechanics. Second Revised Edition. NorthHolland Publishing Company: Amsterdam, 1983. 